\title{
Determining what constitutes an effective psychosocial 'return to work' intervention: a systematic review and narrative synthesis
}

Anthony Venning ${ }^{1 *}$, Tassia K. Oswald ${ }^{1}$, Jeremy Stevenson ${ }^{1}$, Nicci Tepper ${ }^{2}$, Leva Azadi², Sharon Lawn ${ }^{3}$ and Paula Redpath ${ }^{1}$

\begin{abstract}
Purpose: Work can offer a myriad of social and health benefits. Long-term sick leave can be detrimental to employers, individuals, families, and societies. The burden of long-term sick leave has motivated the development of return to work (RTW) interventions. This study sought to determine what constitutes an effective psychosocial RTW intervention, which included exploring whether the level of intervention intensity and intervention characteristics matter to RTW outcomes.

Methods: A systematic review and narrative synthesis were undertaken. Studies were identified through six databases (Ovid Medline, CINAHL (EBSCOhost), Psyclnfo (Ovid), ProQuest, Scopus, and Google Scholar) between 2011 and 3 September 2019. Randomised controlled trials (RCTs) or reviews published in English were eligible for inclusion if they targeted adults who were on sick leave/unemployed trying to return to full-capacity employment, had at least one structured psychosocial RTW intervention, and assessed RTW. Study quality was assessed using checklists from the Joanna Briggs Institute.

Results: Database searching yielded 12,311 records. Eighteen RCTs (comprising 42 intervention/comparison groups), seven reviews (comprising 153 studies), and five grey literature documents were included. Included studies were of moderate-to-high quality. Research was primarily conducted in Europe and focused on psychological or musculoskeletal problems. RTW outcomes included RTW status, time until RTW, insurance claims, and sick days. Participating in a RTW program was superior to care-as-usual. RTW outcomes were similar between diverse interventions of low, moderate, and high intensity. Common foundational characteristics seen across effective RTW interventions included a focus on RTW, psychoeducation, and behavioural activation.

Conclusions: Evidence suggests that a low intensity approach to RTW interventions may be an appropriate first option before investment in high intensity, and arguably more expensive interventions, as the latter appear to provide limited additional benefit. More high-quality RCTs, from diverse countries, are needed to provide stronger evidence.
\end{abstract}

Keywords: Return to work, Intervention, Systematic review, Psychosocial

\footnotetext{
* Correspondence: anthony.venning@flinders.edu.au

'Discipline of Behavioural Health, College of Medicine \& Public Health, Flinders University, South Australia, Australia

Full list of author information is available at the end of the article
}

(C) The Author(s). 2021 Open Access This article is licensed under a Creative Commons Attribution 4.0 International License, which permits use, sharing, adaptation, distribution and reproduction in any medium or format, as long as you give appropriate credit to the original author(s) and the source, provide a link to the Creative Commons licence, and indicate if changes were made. The images or other third party material in this article are included in the article's Creative Commons. licence, unless indicated otherwise in a credit line to the material. If material is not included in the article's Creative Commons licence and your intended use is not permitted by statutory regulation or exceeds the permitted use, you will need to obtain permission directly from the copyright holder. To view a copy of this licence, visit http://creativecommons.org/licenses/by/4.0/ The Creative Commons Public Domain Dedication waiver (http://creativecommons.org/publicdomain/zero/1.0/) applies to the data made available in this article, unless otherwise stated in a credit line to the data. 


\section{Introduction}

Work can offer individuals, families, and wider society a myriad of social and health benefits. From an individual viewpoint, employment can be beneficial for people's health [1] and contribute to greater quality of life [2], as it affords the opportunity for social integration and contributes to social identity [3]. Most industrialised nations recognise long-term sick leave as an increasing public health problem, with significant personal, social, and economic consequences [4-6]. Currently, common mental health disorders and musculoskeletal problems are the leading cause of absence due to sickness in highincome countries $[3,4,7,8]$ and are associated with both significant personal distress and impairment, alongside public economic burden in the form of lost productivity, wages, and early retirement $[3,9]$.

Common mental health disorders are the primary driver behind approximately 30 to $50 \%$ of all disability claims in high-income countries $[9,10]$, with the cost of mental ill-health across the Australian workforce estimated to be almost $\$ 13$ billion in 2015/2016 (approximately $\$ 3200$ per employee with mental illness) [11]. In Australia, musculoskeletal conditions cause more than $85 \%$ of chronic pain and account for over $40 \%$ of early retirements, leading to an annual loss of $\$ 16$ billion in gross domestic product (GDP) [12]. Recognition of the burden associated with long-term sickness absence has motivated policy makers, workplaces, clinicians, and researchers to develop interventions which aim to assist workers to return to work (RTW) and subsequently improving their quality of life. RTW programs respond to the challenge of long-term sickness absence; however, they can be complex and costly [13] and, despite having a shared primary objective of getting people back to work, RTW programs can vary considerably. For example, there is a broad range of interventions in terms of who provides the intervention (e.g., external contractors vs. the workplace themselves) and a broad range of intervention intensities, from low-intensity phone programs to high-intensity supported placements. Furthermore, the contents and methods applied to delivery of RTW interventions can also vary and, at present, no gold standard exists $[3,8]$.

\section{The current study}

There is growing interest from Australian healthcare providers such as allied health organisations who have the capacity to offer RTW interventions, however it is unclear how these interventions should be designed to best get people back to work. This includes uncertainty around what strategies should be implemented and how intense the level of intervention should be. Through summarising the international literature, the current study aimed to determine what constitutes an effective psychosocial 'Return to Work' (RTW) intervention. We define psychosocial interventions as interventions which emphasise psychological, behavioural or social factors rather than biological factors, such as physical health or pharmacotherapy. The current study also aimed to explore whether the level of intervention intensity and intervention characteristics matter to RTW outcomes.

\section{Methods}

\section{Search strategy}

This review drew on the Preferred Reporting Items for Systematic Reviews and Meta Analyses (PRISMA) Guidelines [14]. We systematically searched the following databases between 2011 and 23 July 2019: Ovid Medline, CINAHL (EBSCOhost), PsycInfo (Ovid), ProQuest, Scopus, and Google Scholar. An expert medical librarian helped define the search terms which can be found in Supplementary File 1.

A search of the grey literature was conducted to obtain guidelines and frameworks for RTW best practices that were authored by Australian RTW organisations, given we wanted to address the study aim in the Australian context. The grey literature search involved three strategies recommended by Godin and colleagues [15]. Firstly, an industry expert in the RTW field was contacted for recommendations (a senior manager of a major Australian RTW organisation). This expert provided a list of major RTW organisations in Australia, the websites of which were then searched for relevant documents. An advanced Google search was then conducted using search terms outlined in Supplementary File 1. As recommended, the first 200 Google Scholar results were retained and screened [16].

\section{Inclusion criteria}

Studies were included if they met the following criteria:

- Randomised controlled trials (RCTs) and reviews (systematic or meta-analysis) published in English after 2011 (literature prior to 2011 was reviewed by Hoefsmit, Houkes [1];

- Participants were adults aged 18 years or older on full or partial sick leave, or unemployed, and trying to return to paid employment;

- Interventions focused directly on RTW, or indirectly by addressing a barrier to RTW such as mental illness or pain. At least one of the interventions evaluated in the RCTs, including those in the reviews, needed to be a structured psychosocial intervention that was primarily focused on the individual.

- RTW outcomes were the focus, such as employment status, sickness absence, work-related engagement levels, or disability/insurance claims; or secondary 
outcomes which generally addressed psychological symptoms such as depression, pain, stress, quality of life, or similar.

High intensity interventions such as work placements, overly medical/physical interventions, intensive case management, interventions with excessive focus on other stakeholders (e.g., meetings with employers or staff training), and interventions with minimal structure (e.g., brokerage case management, in which a case manager provides little direct service to the client), were excluded because we were interested in exploring interventions which could be offered by providers with limited capacity (e.g., small teams, non-clinical settings and resources). Grey literature documents needed to be: (1) authored by an Australian RTW organisation, (2) represent a set of guidelines/frameworks for best RTW practices, (3) allow for inferences about effective intervention characteristics, and (4) be published in English language after 2011.

\section{Study screening and selection}

Two authors (JS and AV) independently screened the titles and abstracts of all articles returned by the systematic search. Where abstracts met the inclusion criteria, the full text was reviewed. Reference lists of identified publications were also checked for additional relevant studies which may have been missed in the database search. The two reviewers met to discuss any discrepancies and agreed upon the final studies for inclusion.

\section{Critical appraisal of included studies}

The included studies were critically appraised using checklists from the Joanna Briggs Institute for RCTs or reviews. The checklists assess the quality of each study's methodology, referring to important elements of study. Two authors (JS and TKO) independently appraised the studies. When study ratings were incongruent, the two authors discussed until consensus was reached. A higher percentage score indicates higher quality methodology. Studies with a score of $50 \%$ or less were excluded from the review.

\section{Data extraction and synthesis}

Data were extracted and cross-checked from the included studies by a combination of three review authors (JS, TKO and AV) using data collection tools designed and tested by the review authors.

General study characteristics and results extracted from included RCTs included study location, population, sample size, intervention details, intervention provider(s), RTW outcome(s), and secondary outcome(s). Information about common intervention characteristics were identified and are described in Table 1.

At times, a secondary reference was located (e.g., the $\mathrm{RCT}$ protocol) to gain more detailed information about intervention characteristics. On some occasions,

Table 1 RCT Intervention Characteristics: Description and Categorisation

\begin{tabular}{|c|c|c|}
\hline $\begin{array}{l}\text { Intervention } \\
\text { Characteristic }\end{array}$ & Categorisation & Description \\
\hline $\begin{array}{l}\text { Description of } \\
\text { Intervention }\end{array}$ & N/A & Main components of intervention \\
\hline $\begin{array}{l}\text { Duration (Total } \\
\text { Hours) }\end{array}$ & $\begin{array}{l}\text { Low / Moderate } \\
\text { / High }\end{array}$ & Low $\leq 4$ / Moderate $>4<12$ / High $\geq 12$ \\
\hline Frequency & $\begin{array}{l}\text { Low / Moderate } \\
\text { / High }\end{array}$ & Low $\leq$ monthly / Moderate $>$ monthly $<$ weekly / High $\geq$ weekly \\
\hline Early Timing* & Yes/No & Whether the intervention occurred within 3 months of initial sickness absence \\
\hline Multi-disciplinary & Yes/No & Whether intervention was multi-disciplinary \\
\hline RTW focus & Yes/No & Whether the intervention had some explicit focus on return to work \\
\hline Exposure & Yes/No & $\begin{array}{l}\text { Whether the intervention had some focus on external (e.g., graded RTW) or internal (e.g., mindfulness) } \\
\text { exposure (i.e., confrontation of challenging stimuli) }\end{array}$ \\
\hline $\begin{array}{l}\text { Cognitive } \\
\text { Restructuring }\end{array}$ & Yes/No & Whether the intervention included a focus on cognitive restructuring \\
\hline $\begin{array}{l}\text { Behavioural } \\
\text { Activation }\end{array}$ & Yes/No & $\begin{array}{l}\text { Whether the intervention had a focus on behavioural activation (e.g., exercise, remaining active, activity } \\
\text { scheduling) }\end{array}$ \\
\hline Goal Setting & Yes/No & Whether the intervention included a focus on goal setting \\
\hline Values Clarification & Yes/No & Whether the intervention included a focus on value clarification or identification \\
\hline Problem Solving & Yes/No & $\begin{array}{l}\text { Whether intervention included a focus on problem solving (e.g., identification of barriers and strategies to } \\
\text { overcome these) }\end{array}$ \\
\hline Psychoeducation & Yes/No & Whether intervention included a focus on psychoeducation \\
\hline
\end{tabular}

* $=$ consistent with a previous definition by Loisel and colleagues [17] 
assumptions were made; for example, if a study included a common intervention (e.g., Cognitive Behavioural Therapy), but did not specify the length of each session, it was deemed reasonable to assume that sessions were one hour each, as this is the average duration of an individual psychotherapy session [18].

For the included reviews, data extracted included type of review, objective, study types, participants, and the main findings. For grey literature, data collected included: author, year of publication, title, target population, and relevant recommendations.

Three steps of narrative synthesis, as outlined by Popay and colleagues [19], were followed: (1) develop a preliminary synthesis, (2) explore relationships in the data, and (3) assess the robustness of the synthesised product. In order to develop a preliminary synthesis of findings, the data were (a) organised into groups relating to study design, type of intervention, and setting or context for the intervention; and (b) presented in tabular form.

\section{Results}

\section{Study search and inclusion}

As shown in Fig. 1, database searching yielded 12,311 records. Following the removal of duplicates, 3737 studies were screened by title and abstract, and 3610 studies were excluded. Reference list searching resulted in the identification of an additional 28 relevant studies and the full text of 127 studies were assessed. Thirty-one studies were included, comprising of 22 RCTs and 9 reviews.

For the grey literature, the industry expert suggested several major RTW organisations and websites. However, a search of these organisations websites did not yield any results. An advanced Google search occurred on the 3rd of September 2019. As shown in Fig. 1, the advanced Google search returned 234,000 results. The first 200 results were screened and 157 were excluded by title. Forty-three full documents were reviewed, and 5 documents were subsequently included.

\section{Quality of included studies}

Critical appraisal of the included RCTs $(n=22)$ is displayed in Fig. 2. Four included RCTs [20-23] were removed from the systematic review because they were classified as low quality (appraisal scores $\leq 50 \%$ ). Appraisal scores for the remaining 18 RCTs ranged between 58 and 85\%. Randomisation procedures, statistical analyses performed, trial designs utilised, and measurement of outcomes for intervention and control participants were done appropriately in the majority of the included RCTs.

Most studies utilised administrative or registry data, removing the possibility of assessment bias. The biggest limitation across the majority of the included RCTs was an inability to determine whether the participants themselves, or those delivering the interventions, were blinded. Furthermore, descriptions and considerations of participants lost to follow-up were typically inadequate. Critical appraisal of the included reviews $(n=9)$ is displayed in Fig. 3. Two included reviews $[9,24]$ were removed from the systematic review because they were classified as low quality (45\%). Appraisal scores for the remaining 7 reviews ranged between 64 and 100\%, with three receiving a score of $100 \%$. The main methodological limitations in the included reviews included failing to include grey literature in searches, not using two reviewers to independently appraise studies, and not formally assessing publication bias. The remainder of the checklist items were met by the majority of the reviews.

\section{Randomised controlled trials ( $n=18$ ) \\ General study characteristics}

General characteristics of the included RCTs are shown in Table 2. Eighteen RCTs were included in the review, comprising of 42 intervention/comparison groups. All RCTs were conducted in central or northern Europe, with one study conducted in Canada. Total sample sizes ranged from 60 to 728 participants (Median $(\mathrm{IQR})=$ 217.50 (218.25)). Target populations included individuals with musculoskeletal problems $(n=8$ studies; $44.5 \%)$, psychological problems ( $n=9$ studies; $50 \%)$, and other health issues ( $n=3$ studies; $17 \%)$. Only 3 studies (17\%) explicitly stated that the health problems were workrelated. Participants in the included RCTs had mixed employment status (casual, part-, or full-time). In most studies, participants' sick leave duration was long $(>3$ months) and generally up to 12 months.

Interventions in the included RCTs were typically well-known structured psychosocial interventions, including Cognitive Behaviour Therapy (CBT) and Acceptance and Commitment Therapy (ACT). Other interventions such as coaching and counselling were also used. Four RCTs involved a workplace mediation component and only two interventions involved web-based engagement. Common RTW outcome measures included RTW status (i.e., succeeded or failed in returning to work), time until first or full RTW, disability/insurance claims, and number of sick leave days. Most studies also included secondary outcome measures which generally addressed psychological symptoms such as depression, stress, quality of life, and pain.

\section{Overall study results}

Table 3 presents specific intervention details (including intervention duration, frequency, and psychological strategies used), as well as results from the included RCTs. There were largely no statistically significant 


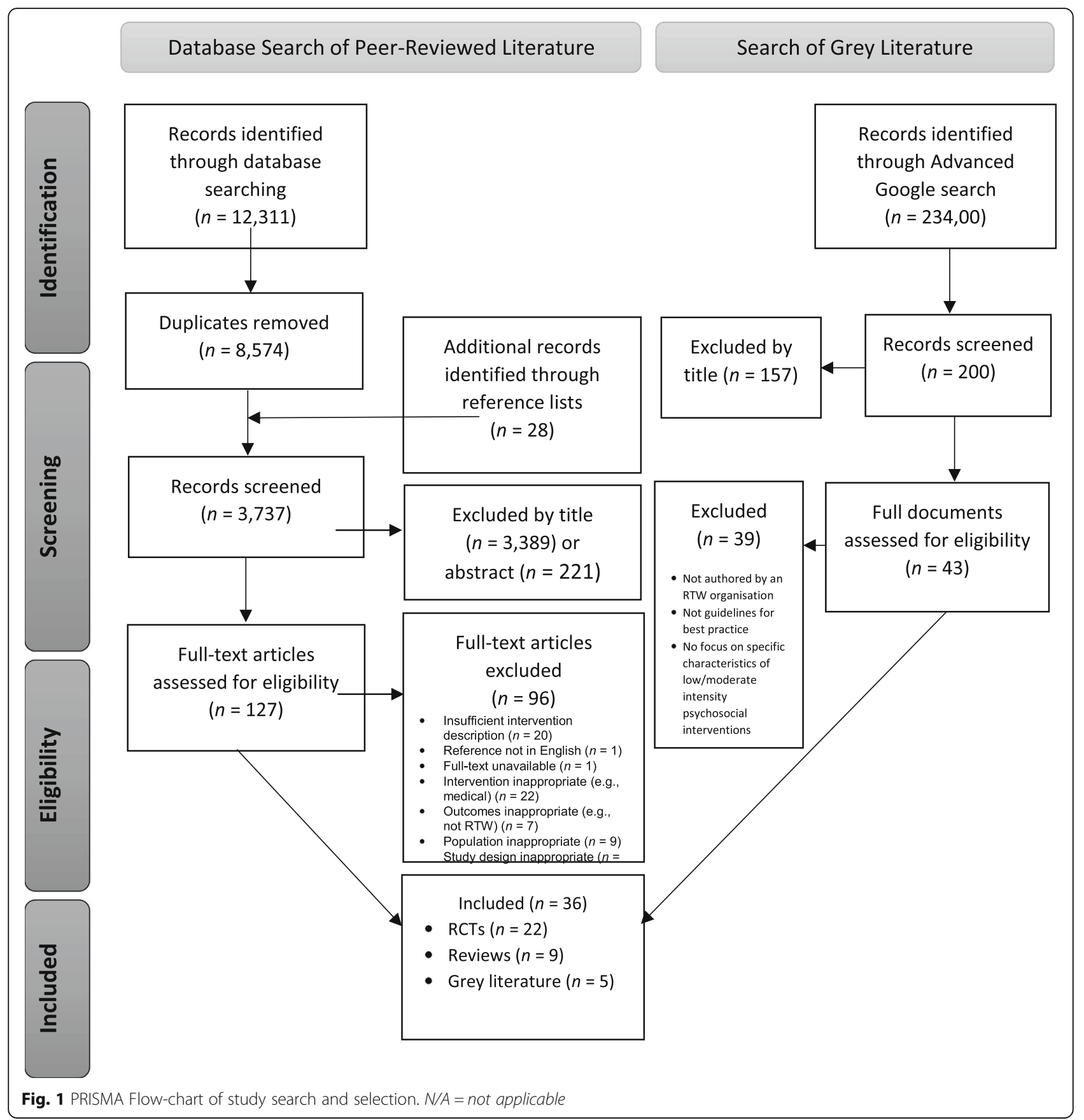

differences on RTW outcomes between participants in diverse RTW interventions across the RCTs. Participants generally had positive outcomes and there was no indication that any of the interventions were detrimental to an individuals' RTW (see Table 3). Eleven of the included RCTs reported on participants RTW outcomes at approximately 1-year follow-up [25-28, 30, 34, 36, 37, 39-41]. The percentage of participants who achieved RTW at 1-year follow-up in these studies varied considerably between and within studies. On average, the average minimum proportion of participants who achieved
RTW at 1-year follow-up within these studies was $56 \%$, while the average maximum proportion of participants who achieved RTW at 1-year follow-up within these studies was $68 \%$ of participants.

\section{Intervention intensity}

Intensity of RTW programs was determined by the frequency and duration of the intervention (see Table 1 for definitions). Where it was possible to determine the frequency and duration of the interventions, we discuss results below. It was not possible to comment on the 


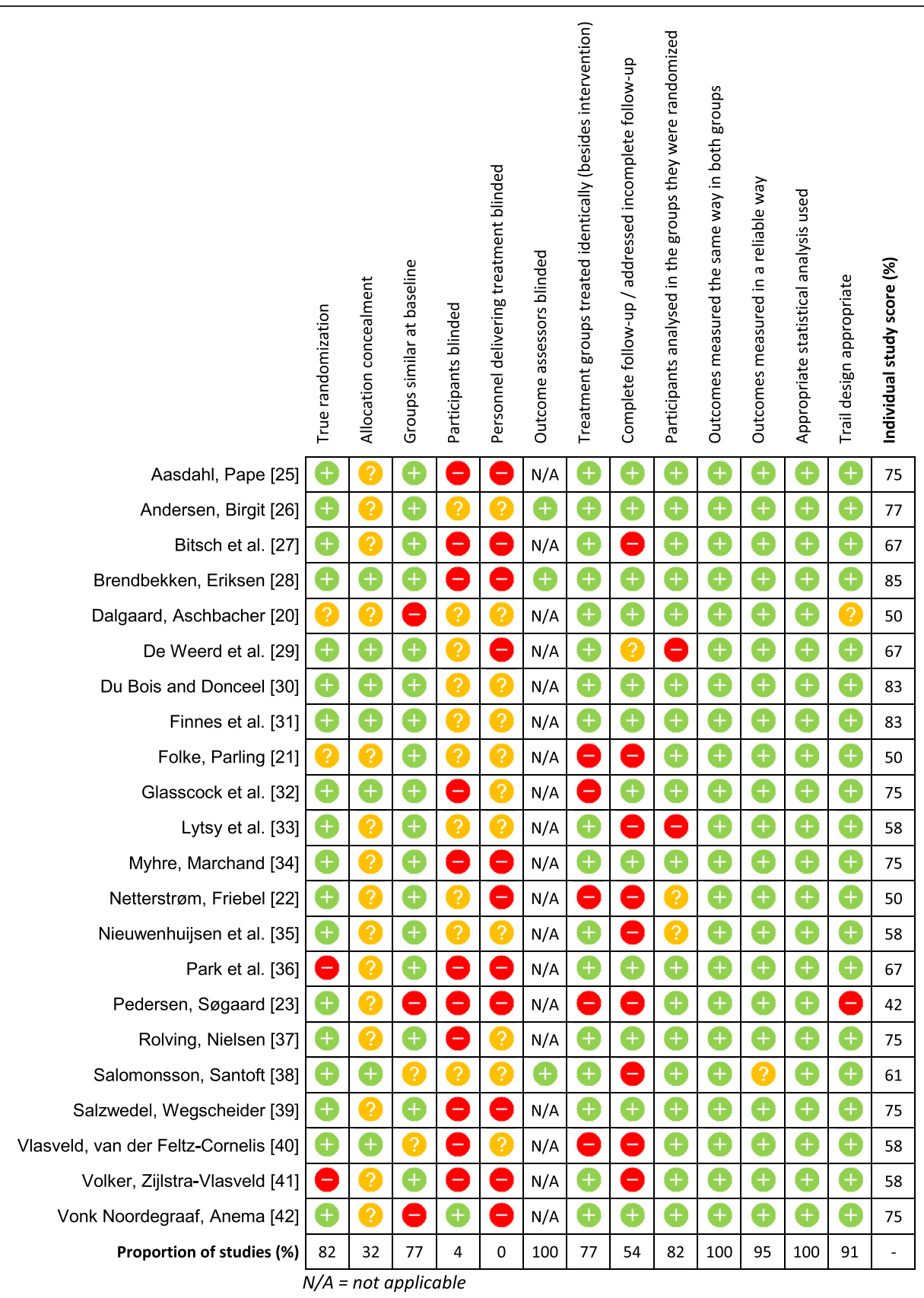

Fig. 2 Critical appraisal of included randomized controlled trials. $N / A=$ not applicable

effect of intervention intensity in 10 RCTs, as they compared interventions of the same intensity $[25,27,28,30$, $31,34,35,37,38,42]$.

In two RCTs, a low-to-moderate intensity intervention was compared with a high intensity intervention [26, 38]. In one of these RCTs, when comparing a low intensity health guidance intervention with either (1) a tailored physical activity program plus health guidance or (2) a chronic pain self-management program plus health guidance, there was no statistically significant difference between participants on measures of RTW, work ability, pain, and kinesiophobia (fear of movement) [26]. In the second RCT, there was also no difference in RTW between participants in a high intensity psychological disorder-focused CBT intervention compared with participants in a moderate intensity RTW-focused CBT intervention [38]. While participants in the high intensity psychological disorder-focused CBT intervention experienced superior reduction of psychiatric symptoms from pre- to post-treatment, participants in the RTW- 


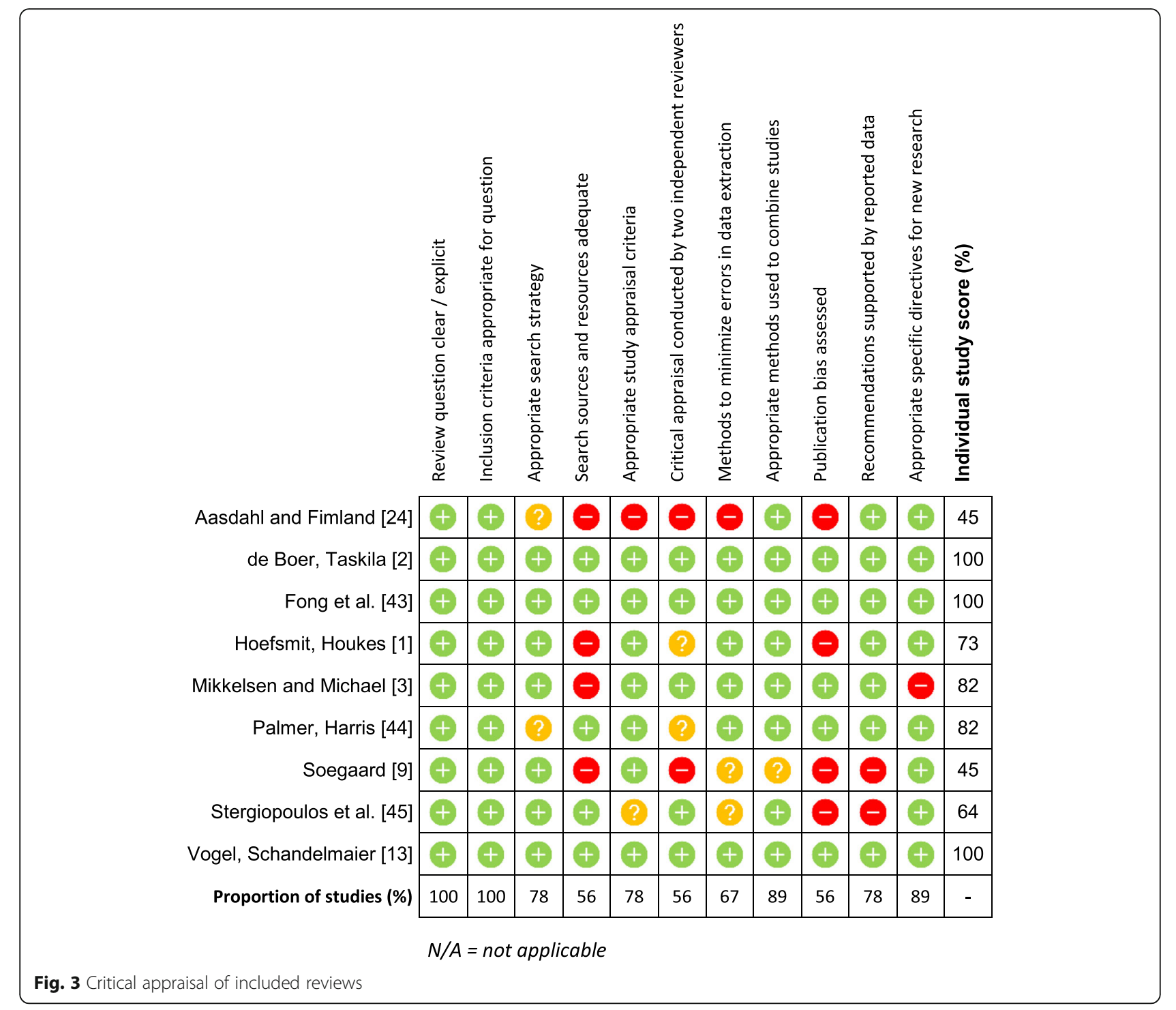

focused CBT intervention experienced greater reduction in psychiatric symptoms from post-treatment to 12 months follow up [38]. One RCT compared a high intensity individual work-focused CBT intervention with a no-treatment comparison group [32]. In this study there was no statistically significant difference between participants on measures of RTW or mental health.

In eight RCTs, participants in an intervention were compared to individuals who were receiving care as usual (CAU) [30, 31, 33, 36, 37, 39-41]. CAU was generally quite broad and varied across studies, including: a disability evaluation [30]; rehabilitation in a standard care facility [31]; 'usual care' provided by regular health contacts [33]; functional restoration [36]; standard preoperative surgery-related information and post-operative physical rehabilitation [37]; cardiac rehabilitation and asneeded counselling [39]; contact with a range of health professionals [40, 41], as well as treatment for mental health problems in some cases [40] and regular consultations with occupational physicians [41]. In 3 of these RCTs, there was no statistically significant difference between CAU or intervention participants on primary outcome measures of RTW [37, 39, 40]. Furthermore, in the same studies there was no statistically significant difference between CAU or intervention participants on secondary outcomes measuring catastrophising [37], fear avoidance [37], pain [37], disability scores [37], work ability [39], mental quality of life [39], or depressive symptoms [40]. In another study, participants in the CAU intervention groups experienced similar outcomes overall; however, when stratifying participants by psychological disorder diagnosis, some between-group differences in sickness absence days, work ability, and psychological symptoms were observed [31]. 


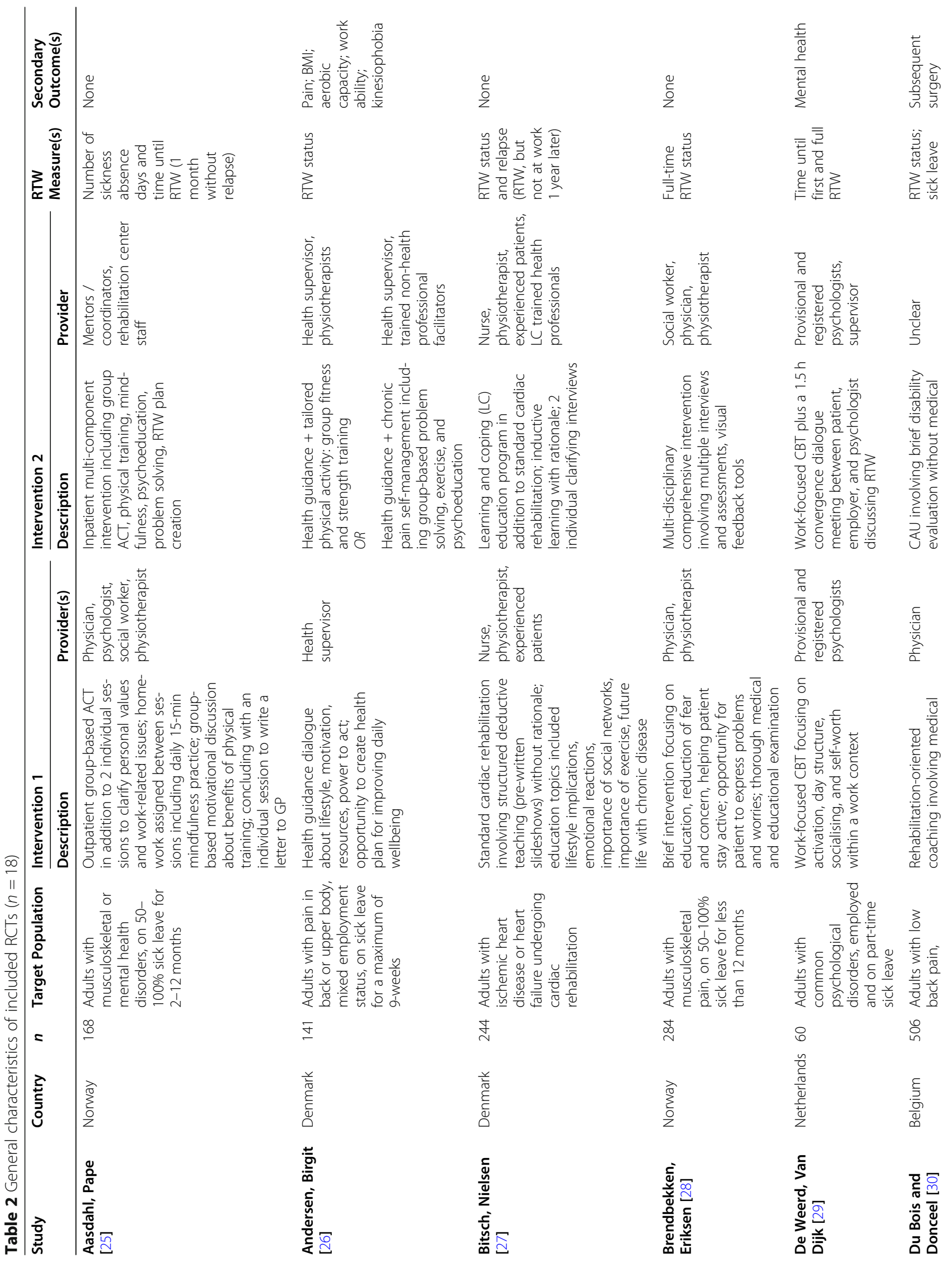




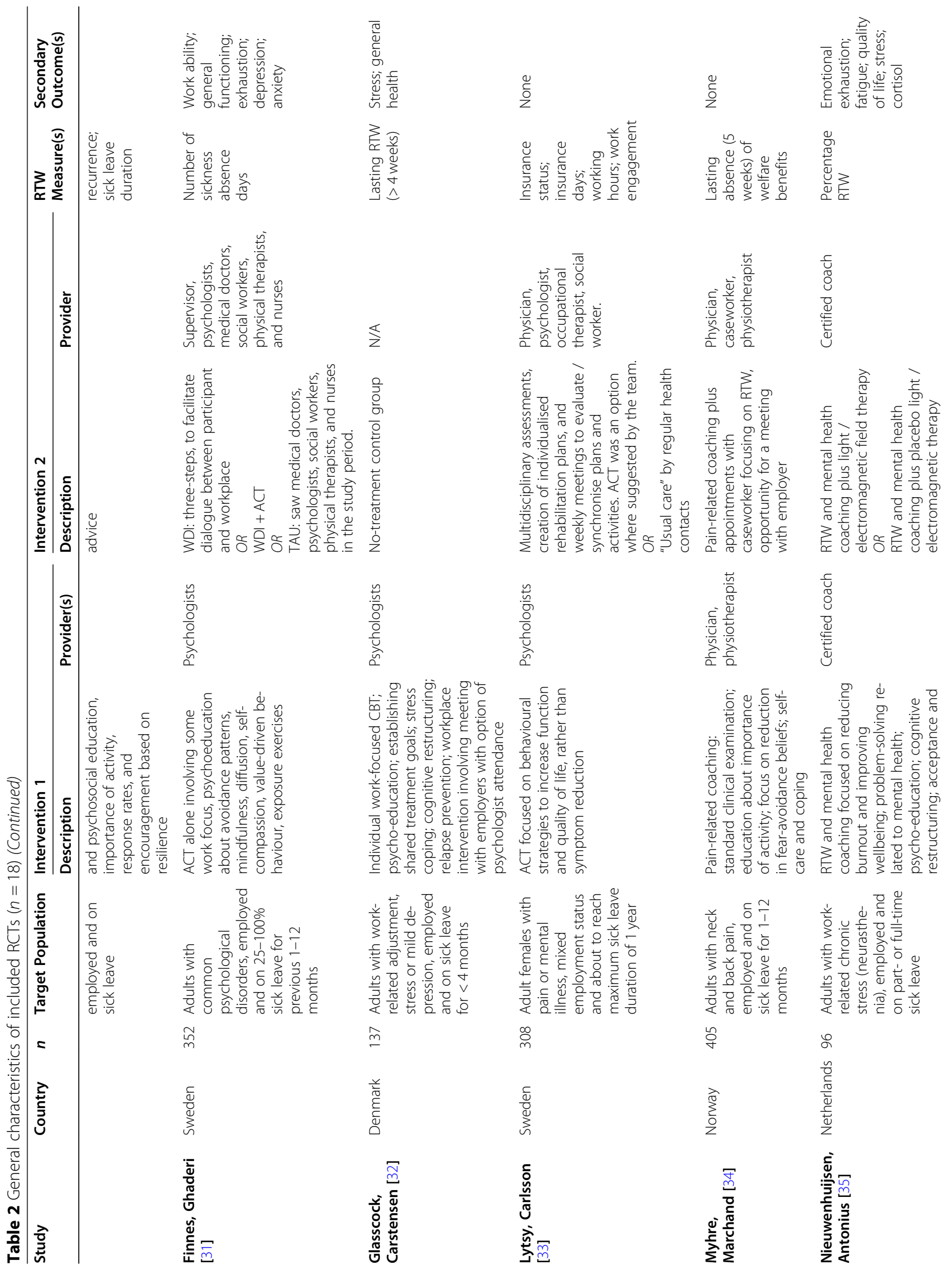




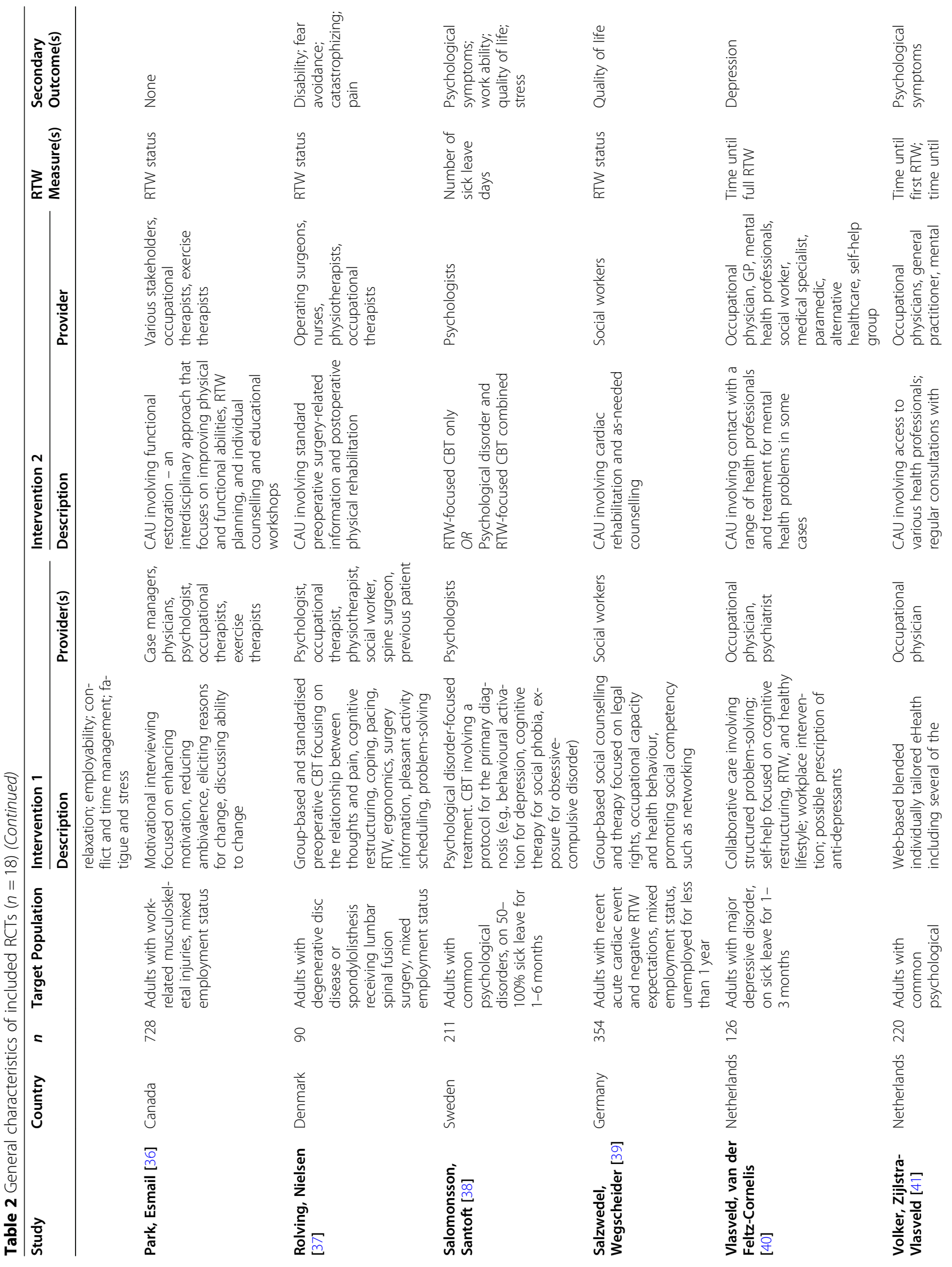




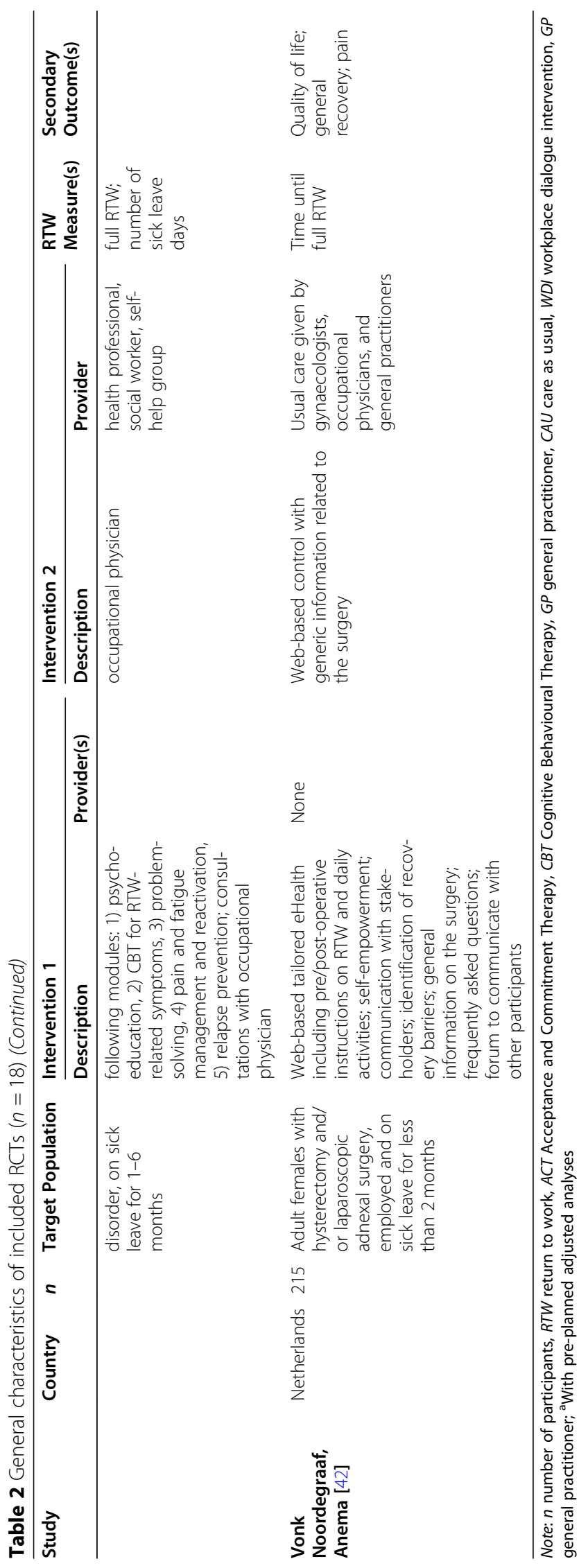




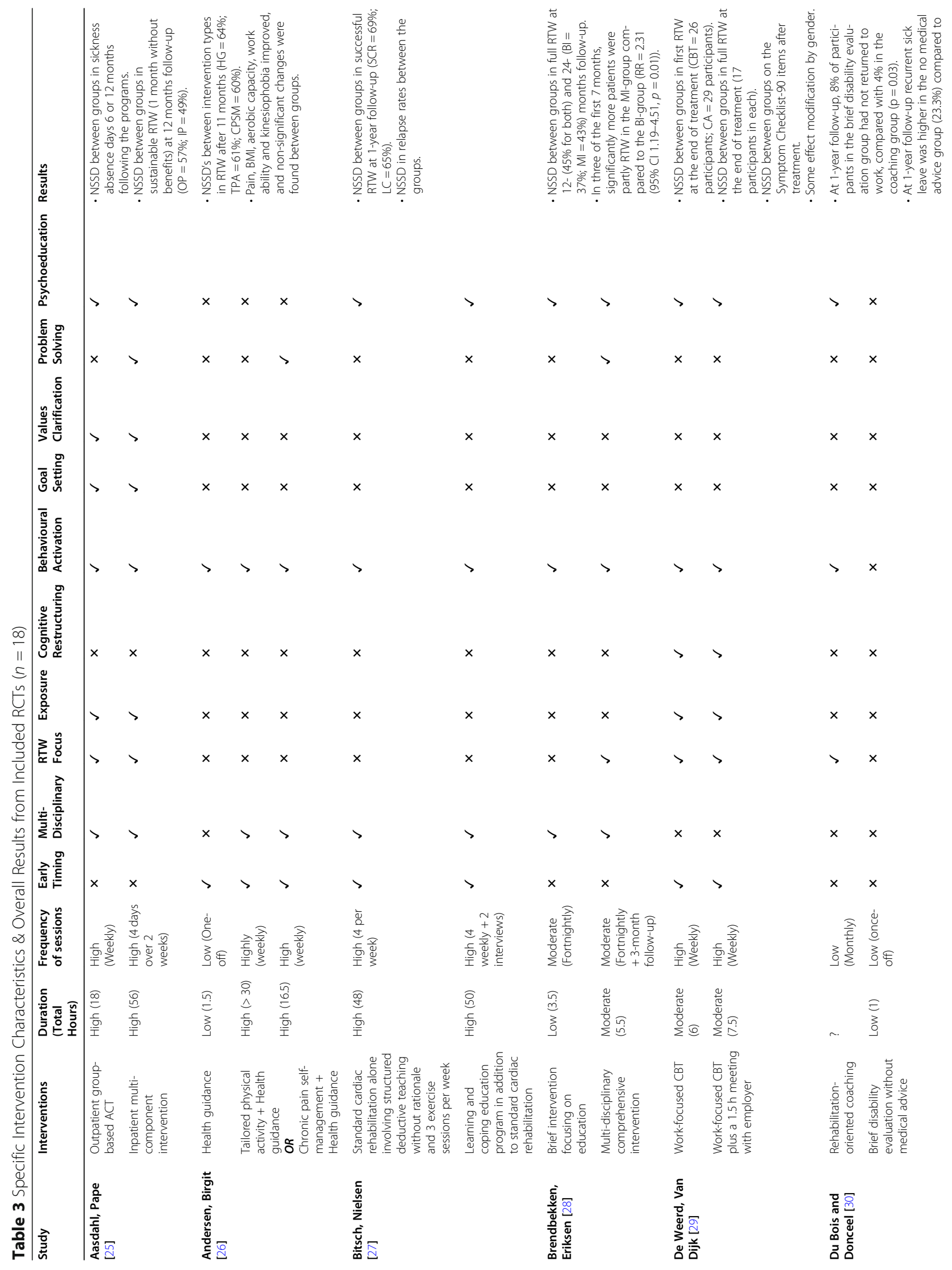




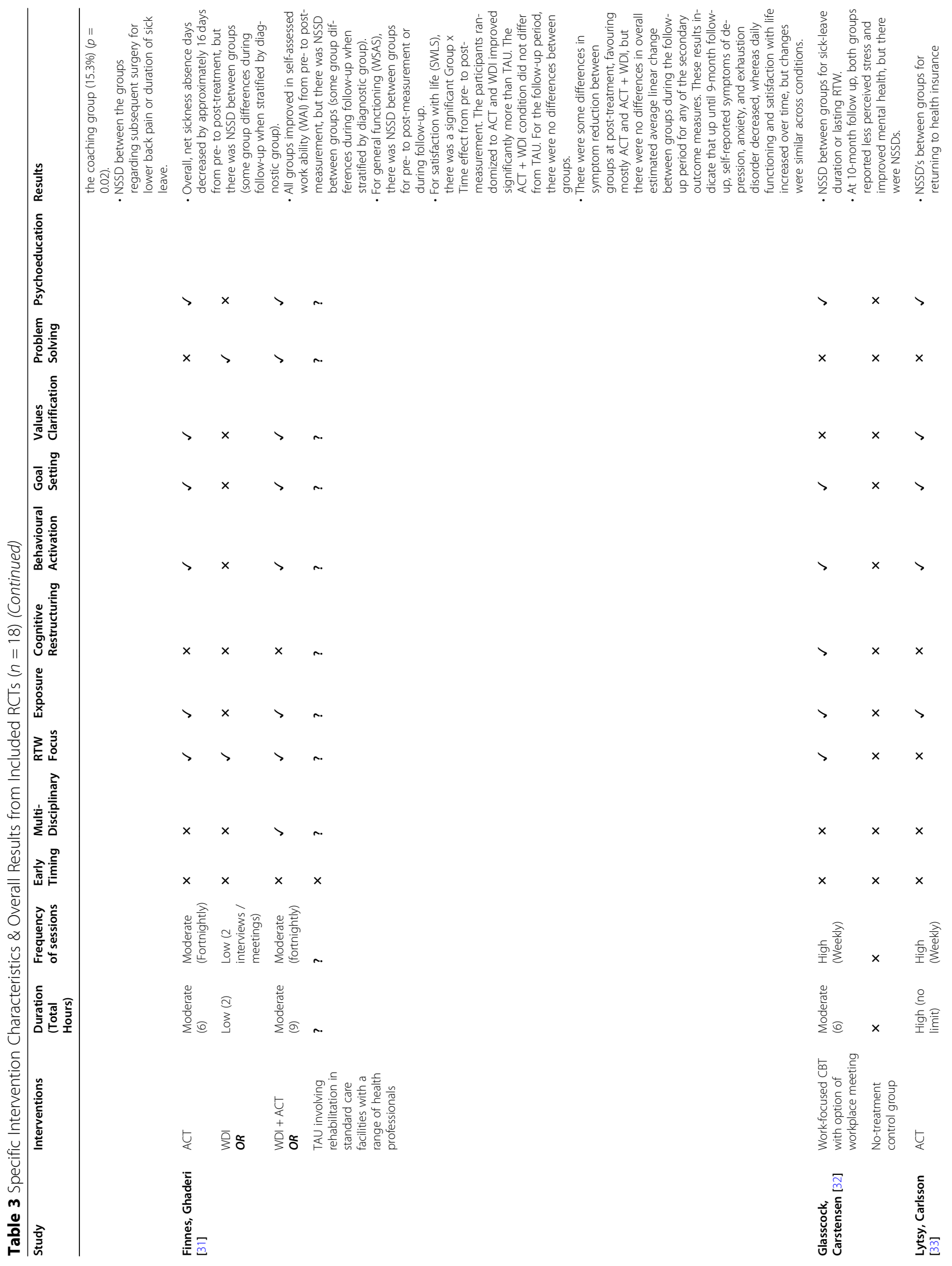




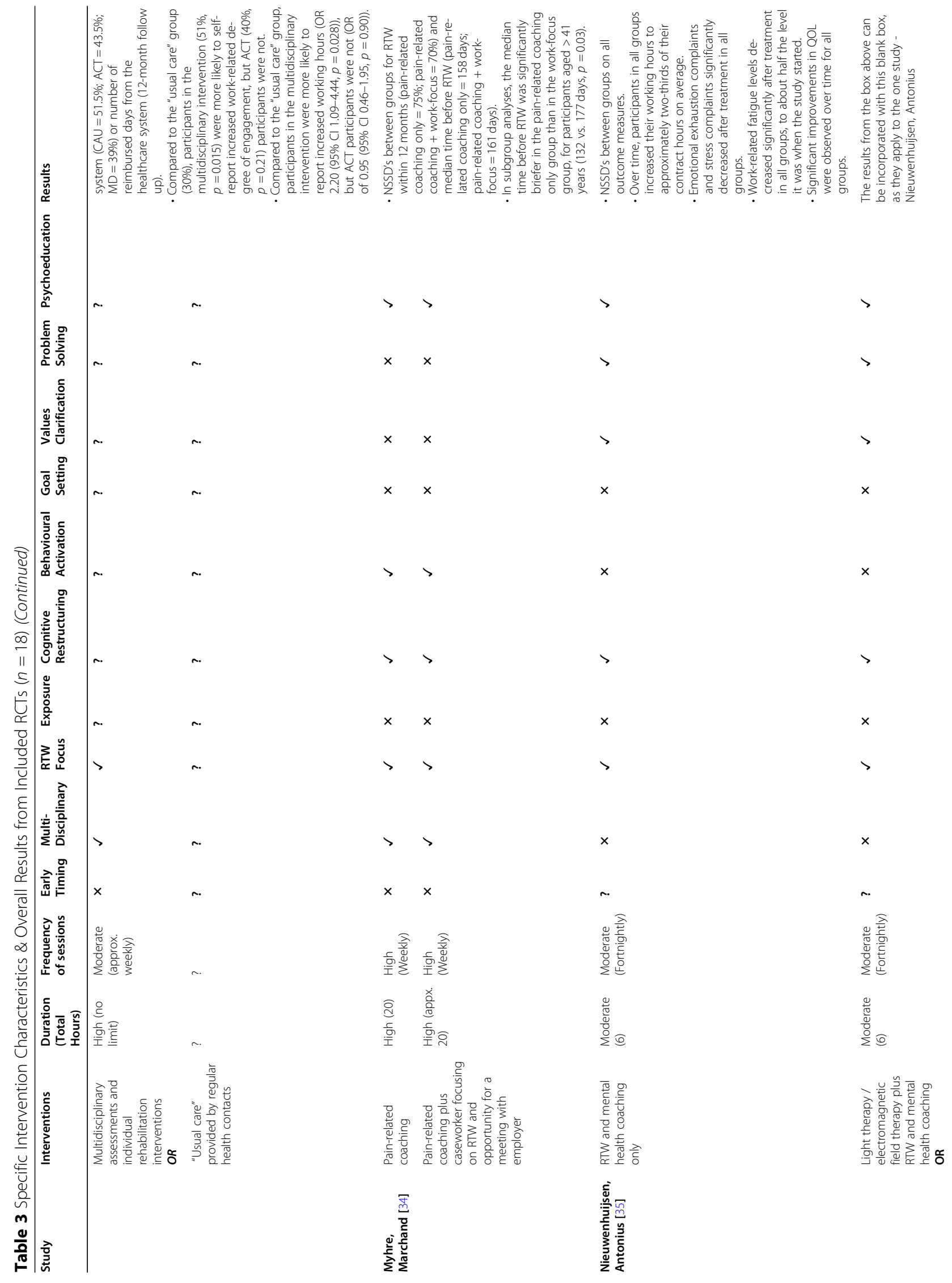


Venning et al. BMC Public Health

(2021) 21:2164

Page 15 of 25

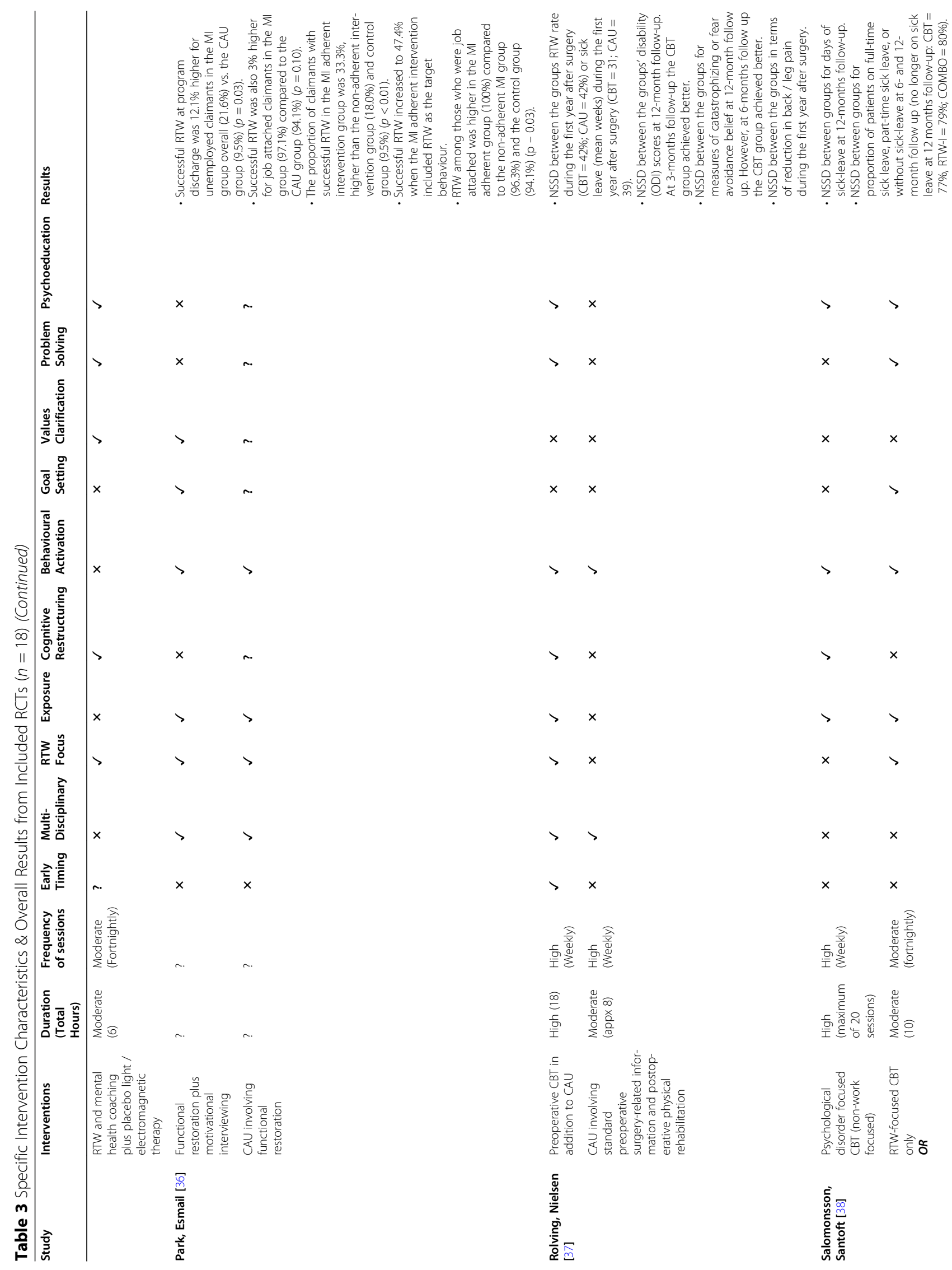




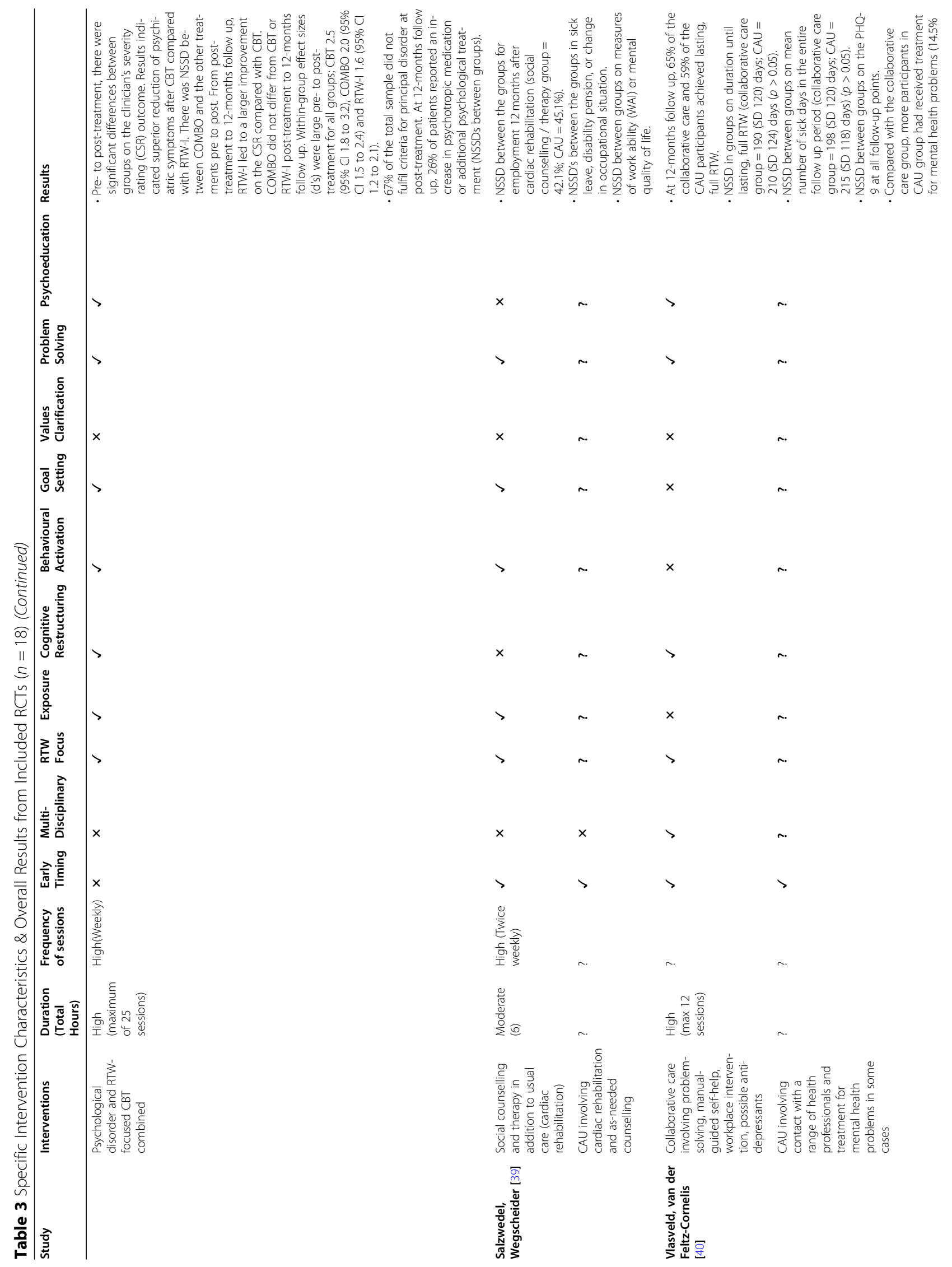




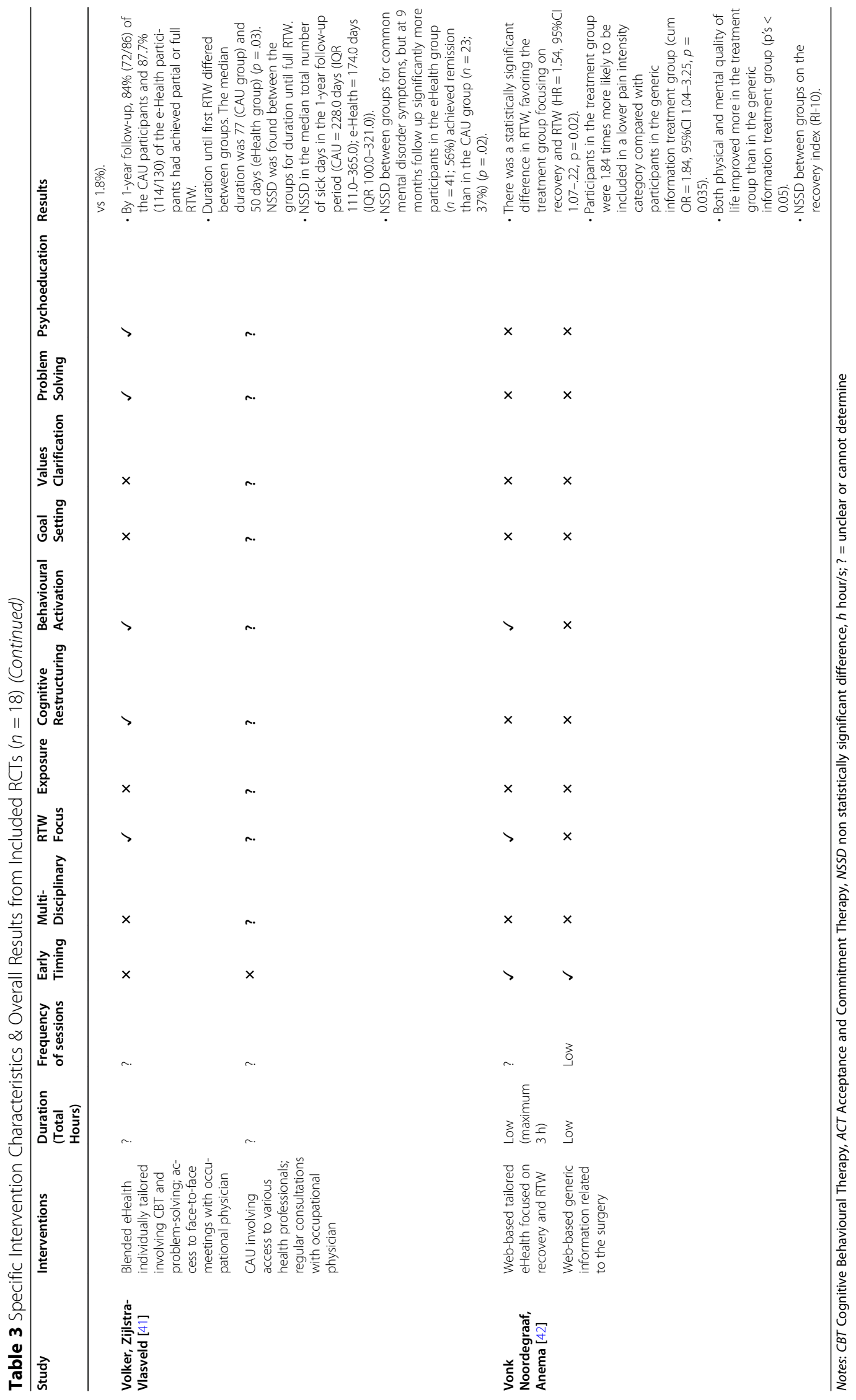


The remaining $4 \mathrm{RCTs}$ showed results in favour of intervention groups over CAU groups. Participants in a rehabilitation-oriented coaching program showed a higher RTW than those who received CAU (disability evaluation with no medical advice) at 1-year follow up [30]. Eight per cent of participants in the CAU group did not return to work, compared to $4 \%$ in the coaching program [29]. Similarly, overall RTW was higher in an intervention group receiving motivational interviewing (21.6\%) compared to a CAU group receiving functional restoration (9.5\%) [36]. In another study, participants in a multi-disciplinary intervention were more likely to self-report increased working hours and work-related engagement compared to participants in a "usual care" group, but participants in an ACT intervention were not [33]. In the last of these RCTs, participants in a CAU group had a slower RTW than participants in a tailored e-Health program (median $=77$ versus 50 days, $p=0.03$ ), but there was no statistically significant between-group difference in full RTW [41].

\section{Intervention characteristics}

Specific characteristics of each intervention in the included RCTs are shown in Table 3. An aggregate summary of these characteristics is also displayed in Table 4. A broad analysis of extracted characteristics from the 42 intervention/comparison groups across the 18 RCTs shows that the inclusion of (1) a RTW focus, (2) behavioural activation, and (3) psychoeducation, were most common across the RTW interventions.

Reviews ( $n=7$ )

General study information, intervention characteristics, and main findings of the included reviews are shown in Table 5. All included reviews were systematic and four included meta-analysis. The reviews generally aimed to broadly evaluate the effectiveness of RTW interventions, except for one study which aimed to investigate the effectiveness of particular intervention characteristics [1]. The total number of studies included in each of the reviews ranged from seven to 42 (153 studies in total), and they were mostly controlled quantitative designs. Four
RCTs included in the current systematic review [29, 33, $34,41]$ were also represented in two of the included reviews $[3,13]$, representing an overlap in $3 \%$ of studies. Target populations in the included reviews were individuals with mental health issues (1 review), work-related PTSD (1 review), musculoskeletal issues ( $n=1$ review), cancer ( 2 reviews), and other health problems resulting in sick leave (2 reviews).

\section{Mental health issues}

Two included reviews reported on the effectiveness of RTW program characteristics for individuals with mental health issues. The systematic review and metaanalysis by Mikkelson and Michael [3] included 39 studies (a total of 38,938 participants) and looked at the effectiveness of RTW interventions for adults on sick leave with common psychological, stress, somatoform, or personality disorders. Findings from this review suggested that interventions with workplace contact, multiple components, and targeting stress disorders were effective for RTW; however, effect sizes/improvements were small. The review also reported that timing, duration, gradual RTW, and therapeutic elements of RTW interventions had no consistent effect. The systematic review by Stergiopolous and colleagues [45] was more specific, focussing solely on adults on sick-leave due to work-related PTSD. This review included one systematic review and six original studies, totalling 212 participants. Findings from this review suggested that there is good preliminary evidence for the effectiveness of exposure techniques in RTW interventions for individuals on sick-leave due to work-related PTSD.

\section{Musculoskeletal issues}

One systematic review, including 42 studies, reported on the effectiveness of RTW interventions for adults on sick leave with musculoskeletal disorders [44]. Findings from this review suggested that interventions which are timed early, low in duration, and include gradual RTW were effective for individuals with musculoskeletal issues; however, effect sizes were only modest.

Table 4 Counts of specific characteristics used in the interventions / comparison groups $(n=42)$ in the included RCTs $(n=18)$

\begin{tabular}{|c|c|c|c|c|c|c|c|c|c|c|}
\hline & \multicolumn{10}{|c|}{ Intervention Characteristics } \\
\hline & $\begin{array}{l}\text { Early } \\
\text { Timing }\end{array}$ & $\begin{array}{l}\text { Multi- } \\
\text { Disciplinary }\end{array}$ & $\begin{array}{l}\text { RTW } \\
\text { Focus } \\
\end{array}$ & Exposure & $\begin{array}{l}\text { Cognitive } \\
\text { Restructuring }\end{array}$ & $\begin{array}{l}\text { Behavioural } \\
\text { Activation }\end{array}$ & $\begin{array}{l}\text { Goal } \\
\text { Setting }\end{array}$ & $\begin{array}{l}\text { Values } \\
\text { Clarification }\end{array}$ & $\begin{array}{l}\text { Problem } \\
\text { Solving }\end{array}$ & Psychoeducation \\
\hline Yes & 14 & 17 & 25 & 15 & 13 & 28 & 10 & 9 & 14 & 24 \\
\hline No & 24 & 21 & 12 & 21 & 22 & 8 & 25 & 26 & 21 & 11 \\
\hline Unclear & 4 & 4 & 5 & 6 & 7 & 6 & 7 & 7 & 7 & 7 \\
\hline $\begin{array}{l}\text { Overall } \\
\text { (\%) }\end{array}$ & 33 & 40 & 60 & 36 & 31 & 67 & 24 & 21 & 33 & 57 \\
\hline
\end{tabular}


Table 5 General study information, intervention characteristics, and findings from included reviews

\begin{tabular}{|c|c|c|c|c|c|}
\hline Author (year) & $\begin{array}{l}\text { Type of } \\
\text { review }\end{array}$ & Objective & $\begin{array}{l}\text { Study } \\
\text { Types }\end{array}$ & Participants & Findings \\
\hline $\begin{array}{l}\text { de Boer, } \\
\text { Taskila [2] }\end{array}$ & $\begin{array}{l}\text { Systematic } \\
\text { review \& } \\
\text { meta- } \\
\text { analysis }\end{array}$ & $\begin{array}{l}\text { Evaluate the } \\
\text { effectiveness of RTW } \\
\text { interventions }\end{array}$ & 15 RCTs & $\begin{array}{l}\text { Adults with cancer diagnosis } \\
\text { and employed }(n=1835)\end{array}$ & $\begin{array}{l}\text { Low quality evidence that psycho-educational } \\
\text { interventions are equivalent to CAU. Moder- } \\
\text { ate quality evidence that multi-disciplinary in- } \\
\text { terventions are superior to CAU. }\end{array}$ \\
\hline $\begin{array}{l}\text { Fong, Murphy } \\
\text { [43] }\end{array}$ & $\begin{array}{l}\text { Systematic } \\
\text { review \& } \\
\text { meta- } \\
\text { analysis }\end{array}$ & $\begin{array}{l}\text { Evaluate the } \\
\text { effectiveness of RTW } \\
\text { interventions }\end{array}$ & $\begin{array}{l}8 \mathrm{RCTs}, 4 \\
\text { quasi- } \\
\text { experimental }\end{array}$ & $\begin{array}{l}\text { Adults with current or past } \\
\text { cancer diagnosis }(n=2151)\end{array}$ & $\begin{array}{l}\text { Multi-component interventions, including one } \\
\text { or more behavioural, psychological, } \\
\text { educational or vocational component appear } \\
\text { to improve employment status for cancer } \\
\text { patients, but high risk of bias in the literature } \\
\text { means results should be interpreted with } \\
\text { caution. Methodological limitations make } \\
\text { isolating specific components difficult. }\end{array}$ \\
\hline $\begin{array}{l}\text { Hoefsmit, } \\
\text { Houkes [1] }\end{array}$ & $\begin{array}{l}\text { Systematic } \\
\text { review }\end{array}$ & $\begin{array}{l}\text { Investigate } \\
\text { intervention } \\
\text { characteristics that } \\
\text { facilitate RTW }\end{array}$ & $\begin{array}{l}18 \\
\text { quantitative, } \\
5 \text { systematic } \\
\text { reviews }\end{array}$ & $\begin{array}{l}\text { Adults on sick leave for any } \\
\text { reason ( } n \text { unclear) }\end{array}$ & $\begin{array}{l}\text { Generally, early timed (within 6-weeks of ini- } \\
\text { tial sick leave) and multi-disciplinary RTW in- } \\
\text { terventions are effective. For musculoskeletal- } \\
\text { related sick leave, time-contingent and acti- } \\
\text { vating (e.g., gradual RTW) interventions are } \\
\text { effective. }\end{array}$ \\
\hline $\begin{array}{l}\text { Mikkelsen and } \\
\text { Michael [3] }\end{array}$ & $\begin{array}{l}\text { Systematic } \\
\text { review \& } \\
\text { meta- } \\
\text { analysis }\end{array}$ & $\begin{array}{l}\text { Investigate the } \\
\text { effectiveness of RTW } \\
\text { interventions }\end{array}$ & $\begin{array}{l}31 \mathrm{RCTs}, 8 \\
\text { controlled } \\
\text { trials }\end{array}$ & $\begin{array}{l}\text { Adults on sick leave with } \\
\text { common psychological, stress, } \\
\text { somatoform, or personality } \\
\text { disorders }(n=38,938)\end{array}$ & $\begin{array}{l}\text { Timing, duration, gradual RTW, and } \\
\text { therapeutic elements had no consistent } \\
\text { effect. Interventions with workplace contact } \\
\text { and multiple components were effective. } \\
\text { Interventions targeting stress disorders were } \\
\text { effective. Effect sizes / improvements were } \\
\text { small. }\end{array}$ \\
\hline $\begin{array}{l}\text { Palmer, Harris } \\
\text { [44] }\end{array}$ & $\begin{array}{l}\text { Systematic } \\
\text { review }\end{array}$ & $\begin{array}{l}\text { Investigate the } \\
\text { effectiveness of RTW } \\
\text { interventions }\end{array}$ & $\begin{array}{l}34 \text { RCTs, } 8 \\
\text { cohort } \\
\text { studies }\end{array}$ & $\begin{array}{l}\text { Adults on sick leave with } \\
\text { musculoskeletal disorders ( } \\
\text { unclear) }\end{array}$ & $\begin{array}{l}\text { Early timed and low duration interventions } \\
\text { were effective. Interventions that included } \\
\text { gradual RTW were effective. Effects were only } \\
\text { modest. The other characteristics were } \\
\text { ineffective. }\end{array}$ \\
\hline $\begin{array}{l}\text { Stergiopoulos, } \\
\text { Cimo [45] }\end{array}$ & $\begin{array}{l}\text { Systematic } \\
\text { review }\end{array}$ & $\begin{array}{l}\text { Investigate the } \\
\text { effectiveness of RTW } \\
\text { interventions }\end{array}$ & $\begin{array}{l}1 \text { systematic } \\
\text { review, } 3 \\
\text { RCTs, } 3 \text { pre- } \\
\text { post }\end{array}$ & $\begin{array}{l}\text { Adults on sick leave with work- } \\
\text { related PTSD ( } n=212 \text {, in } 6 \text { ori- } \\
\text { ginal studies) }\end{array}$ & $\begin{array}{l}\text { There was good preliminary evidence for the } \\
\text { effectiveness of exposure in RTW } \\
\text { interventions. }\end{array}$ \\
\hline $\begin{array}{l}\text { Vogel, } \\
\text { Schandelmaier } \\
{[13]}\end{array}$ & $\begin{array}{l}\text { Systematic } \\
\text { review \& } \\
\text { meta- } \\
\text { analysis }\end{array}$ & $\begin{array}{l}\text { Investigate the } \\
\text { effectiveness of RTW } \\
\text { interventions } \\
\text { compared to CAU }\end{array}$ & 14 RCTs & $\begin{array}{l}\text { Adults on sick leave or with } \\
\text { disability }(n=12,568)\end{array}$ & $\begin{array}{l}\text { Review found that RTW programs had no } \\
\text { effects compared to usual practice on RTW } \\
\text { outcomes. }\end{array}$ \\
\hline
\end{tabular}

Note: $C A U$ care as usual

antervention characteristics were only included if they were relevant to the current study (i.e., components of low/medium intensity psychosocial interventions). ${ }^{\mathrm{b}}$ Feedback referred to interventions that involved psychological screening followed by individual feedback (e.g., coping strategies) in the case of positive diagnosis.

\section{Cancer}

Two systematic reviews with meta-analyses reported on the effectiveness of RTW program characteristics for individuals with cancer. The systematic review and metaanalysis by de Boer and colleagues [2] included 15 RCTs (a total of 1835 participants) and evaluated the effectiveness of RTW interventions for employed adults with a cancer diagnosis. Findings from this review suggested that psycho-educational interventions are equivalent to care-as-usual in terms of RTW; however, the quality of evidence drawn upon was quite low, meaning this finding may be unreliable. When drawing upon moderate quality RCTs only, the review found that multidisciplinary interventions were superior to care-as-usual for adults with a cancer diagnosis. The systematic review and meta-analysis by Fong and colleagues [43] included
12 studies (a total of 2151 participants) and evaluated the effectiveness of RTW interventions for adults with a current or past cancer diagnosis. Similar to findings by de Boer and colleagues [2], this review reported that multi-component interventions, including one or more behavioural, psychological, educational, or vocational component appeared to improve employment status for cancer patients; however, again, high risk of bias in the available literature means results should be interpreted with caution.

\section{Other sick leave}

Two systematic reviews reported on the effectiveness of RTW interventions for individuals on sick leave for any reason. The systematic review by Hoefsmit and colleagues [1] aimed to investigate specific intervention 
characteristics that facilitate RTW. This review included 18 quantitative studies and five systematic reviews. Findings from this review suggest that, early timed (within 6weeks of initial sick leave) and multi-disciplinary RTW interventions were generally effective. More specifically, for musculoskeletal-related sick leave, time-contingent and activating (e.g., gradual RTW) interventions were effective. The systematic review (and meta-analysis) by Vogel and colleagues [13] aimed to investigate the effectiveness of RTW interventions, compared to care-asusual, for adults on sick leave or with disability. The review included 14 RCTs, with a total of 12,568 participants. The review found that RTW programs had no effects compared to usual practice on RTW outcomes.

\section{Grey literature $(n=5)$}

Information about the grey literature documents and recommendations are shown in Table 6. Target populations included people with psychological problems $(n=$ $2)$, people with any injury or illness $(n=2)$, and people who had experienced a motor vehicle accident $(n=1)$. All injuries and illnesses of the target populations were work-related. The four most recent published documents (Comcare, 2014; CPT Insurance Regulator, 2018; Safe Work Australia, 2018; Worksafe Tasmania, 2018) have based their recommendations at least to some extent on the earliest document by Comcare (2012), which appears to be a central model for RTW processes in Australia.

\section{RTW guidelines for individuals with work-related psychological problems}

Comcare (2014) and Safe Work Australia (2018) provide RTW guidelines for individuals on sick leave due to work-related psychological problems. Both of these guidelines recommend that in assisting RTW for individuals with work-related psychological problems, the response or intervention must be: (1) early; (2) use problem solving strategies; (3) include planning, goal setting, and progress reviews; (4) target and improve work capacities and identify suitable duties; and, (5) encourage the worker to pursue/activate RTW.

\section{RTW guidelines for individuals with work-related injury, illness, or motor vehicle trauma}

Comcare (2012), CPT Insurance Regulator (2018), and Worksafe Tasmania (2018) provide RTW guidelines for individuals on sick leave due to work-related injury, illness, or motor vehicle trauma. Overall, guidelines from the three sources are very similar and recommend that in assisting RTW for individuals with work-related injury, illness, or motor vehicle trauma, interventions should: (1) use evidence-based treatments; (2) provide education about the injuries/illnesses and psychoeducation about cognitive-behavioural models of wellbeing; (3) encourage maintenance or increase of activities (e.g., at home or work); (4) facilitate selfmanagement using pacing and graded exposure to activities; (5) address unhelpful beliefs (e.g., fear-avoidance, catastrophizing, and low self-efficacy); (6) use SMART goals (particularly to facilitate RTW); and, (7) measure and demonstrate effectiveness of treatments/interventions by tracking progress.

\section{Discussion}

This systematic review sought to determine what constitutes an effective RTW intervention. Eighteen RCTs and seven reviews (all moderate-to-high quality) were included. Most studies came from central or northern Europe, and target populations primarily included individuals with musculoskeletal problems and psychological problems. RTW success was primarily considered in terms of employment status, sickness absence, workrelated engagement levels, and disability/insurance claims; however, secondary outcomes including psychological symptoms, pain, and quality of life were also considered, which is a strength of the review. Interventions were typically well-known structured psychosocial interventions, including $\mathrm{CBT}$ and $\mathrm{ACT}$. Key findings are discussed below.

The first key finding from the systematic review is that RTW interventions are worthwhile as they appear to help people get back to work, with the limited evidence suggesting that participating in specified RTW programs may be superior for RTW outcomes than receiving care as usual (CAU). Four RCTs comparing RTW interventions with CAU showed results in favour of the intervention groups [30, 33, 36, 41], while another four RCTs found similar RTW outcomes between individuals participating in a RTW program and those receiving CAU $[31,37,39,40]$. It is important to note that CAU was quite extensive in some cases, which may mean the effects of some RTW interventions were potentially underestimated. For example, in regard to participants who were receiving CAU, studies reported that these individuals actually had relatively high levels of engagement with health care providers such as psychologists or occupational physicians, and were often involved in physical therapies, pain management, psychological therapies, and counselling. In examining the intervention descriptions (Tables 4 \& 5), it was not possible to determine whether 'usual care' from health practitioners was more intensive than the interventions being assessed. If control participants did engage in higher intensity treatments than intervention participants, the effects of the interventions would be underestimated considerably. Future studies should try to avoid this issue by including detailed reporting of study 
Table 6 Document information and recommendations for RTW from included grey literature

\begin{tabular}{|c|c|c|c|c|}
\hline Author & Year & Title & Target Population & Relevant Recommendations \\
\hline Comcare & 2012 & $\begin{array}{l}\text { Clinical Framework for the Delivery of } \\
\text { Health Services }\end{array}$ & $\begin{array}{l}\text { People on sick leave } \\
\text { due to any work- } \\
\text { related injury or } \\
\text { illness }\end{array}$ & $\begin{array}{l}\text { Measure and demonstrate effectiveness of } \\
\text { treatment (e.g., track modifiable factors such as } \\
\text { depression, use valid and reliable measures); } \\
\text { provide education about nature of injury/illness } \\
\text { and psychoeducation about cognitive- } \\
\text { behavioural models of wellbeing; encourage } \\
\text { maintenance of activity in all life domains; ad- } \\
\text { dress unhelpful beliefs related to fear-avoidance, } \\
\text { catastrophising, lack of acceptance, low self- } \\
\text { efficacy, blame, and perception of injustice; facili- } \\
\text { tate self-management through techniques such } \\
\text { as collaborative goal setting, pacing, relaxation, } \\
\text { exposure); implement SMART (specific, measur- } \\
\text { able, achievable, relevant, timed) goals focused } \\
\text { on optimising function, participation, and RTW; } \\
\text { use evidence-based treatments }\end{array}$ \\
\hline
\end{tabular}
$\begin{aligned} & 2014 \text { Working for Recovery: Suitable employment } \\ & \text { for return to work following psychological } \\ & \text { injury }\end{aligned}$

CTP

Insurance

Regulator
People on sick leave due to work-related psychological problems

People on sick leave who have experienced motor vehicle trauma

People on sick leave due to work-related psychological problems
Safe Work
Australia

Worksafe Tasmania
2018 Managing workplace injuries in Tasmania: A handbook for primary treating medical practitioners
Respond early; perform a detailed assessment; clarify work capacity; identify suitable duties; identify participant strengths; promote activation at home, work, and in community; use problem solving strategies; create a RTW plan including goal setting; organise gradual RTW; address maladaptive beliefs about pain and injury; develop healthy coping strategies; increase perceived control; address relapse prevention

Intervene early; focus on person, not the injury; measure and demonstrate the effectiveness of treatment (e.g., outcome measures about goals or work status); address unhelpful beliefs (e.g. about pain and treatment expectancies); increase engagement in activities at home and work as soon as possible; provide education about the nature of the injury; facilitate a self-management plan; create SMART goals; use evidence-based treatment

Provide early intervention (within 3-months of initial sick leave); focus on worker; use collaborative care; problem solve barriers to RTW; encourage worker to pursue RTW opportunities; engage in follow-up contact with worker (face-to-face or via telephone) to discuss milestones and turning points; use plain English in documentation; assess and align worker expectations; screen for biopsychosocial risk factors (e.g., health conditions, financial stress); establish a review and evaluation process based on agreed goals; use an explicit work-focus; target and improve RTW expectancies of worker (e.g., with motivational interviewing); use complimentary contact modes of telephone and web-based delivery to prevent delays or if worker lives rurally

Measure and demonstrate the effectiveness of treatment (e.g., track progress); address psychosocial barriers such as unhelpful beliefs and coping strategies, financial insecurity, low motivation; optimise expectations of worker (e.g., beliefs in recovery); promote benefits of remaining active (e.g., maintaining normal activities); focus on worker strengths; provide education about injury/illness and treatment; use SMART goals focused on function and RTW; promote healthy living habits (e.g., good diet, exercise, sleep, relaxation); promote a pacing approach of graded exposure to activities; use evidence-based treatment

\section{Source}

Comcare

Comcare

\section{CTP}

Insurance Regulator (2018)

Safe Work Australia (2018)

Worksafe Tasmania (2018) related injury or illness 
methodologies [43], explicitly specifying CAU activities, and attempting to avoid contamination.

The reviews included in the current systematic review largely mirror results from the included RCTs, suggesting that RTW interventions are effective for individuals with mental health issues $[3,45]$, musculoskeletal problems [44], cancer [2], and other health issues [1], but also pointing out potential limitations across the available literature. For example, the Mikkelsen and Michael [3] and Palmer, Harris [44] reviews reported RTW effect sizes to be small-modest, while the review by de Boer, Taskila [2] found that RTW interventions were superior to CAU only when considering moderate quality RCTs (e.g., excluding low quality RCTs). Similarly, the review by Fong, Murphy [43] found that RTW interventions were better than CAU but also highlight the high risk of bias in the literature. Given the overall quality of a study predicts the obtained effect size, there is a need to interpret such literature with caution $[9,46]$.

The second key finding from the systematic review is that low-to-moderate intensity interventions may potentially be a good place to start, given the costs and resources required are less than that of higher intensity interventions which appear to provide limited additional benefits. Where it was possible to determine the intensity of RTW interventions (based on the frequency and duration of intervention contact), we explored whether low-to-moderate intensity interventions could yield similar results to high intensity RTW programs. In two RCTs a low-to-moderate intensity intervention was compared with a high intensity intervention. In one of these studies, there was no statistically significant difference between participants on measures of RTW, work ability, pain, and kinesiophobia (fear of movement), when comparing a low intensity health guidance intervention with either a tailored physical activity intervention plus health guidance, or with a chronic pain self-management intervention plus health guidance [26]. In the other study, there was also no difference in RTW outcomes between participants in a high intensity psychological disorder-focused CBT intervention compared with participants in a moderate intensity RTW-focused CBT intervention [38]. These studies, along with the other RCTs which found very few statistically significant differences in RTW outcomes for individuals in interventions of varying intensities, provide preliminary support for a stepped-approach to RTW interventions starting with low-to-moderate intensity. However, future research should work towards understanding around whether different sub-groups, or more complex RTW clients, would benefit from varying intervention intensities.

The third key finding from the systematic review is that several common characteristics were consistently seen across effective RTW interventions. Across the studies included in our systematic review, a great breadth and variety of intervention characteristics were observed. A broad analysis of these characteristics showed that the application of a RTW Focus, Behavioural Activation, and Psychoeducation were most common across the RTW interventions. Given the relative success of all interventions presented in our systematic review, these may be potentially important characteristics for ensuring successful RTW program outcomes. However, more rigorous research is needed to confirm the specific role of these characteristics in potentially contributing to an intervention's success. Common mental disorders and musculoskeletal problems are the leading cause of sickness absence in high-income countries $[3,4,7,8]$. This was represented in our systematic review, with the majority of participant samples including individuals with either psychological issues $[25,29,31-$ $33,35,38,40,41]$ or musculoskeletal problems $[25,26$, $28,30,33,34,36]$ which affected their work participation. According to a number of meta-analyses, psychoeducation [47-49] and behavioural activation [50-54] can contribute to improved health outcomes for individuals experiencing musculoskeletal pain and mental health difficulties. As such, the application of these strategies to these populations is considered to be appropriate. Psychoeducation and Behavioural Activation are also relatively inexpensive, easy to implement, and broadly acceptable to people [48], making them good foundational strategies when designing low-to-moderate intensity RTW interventions.

\section{Practical recommendations}

The reciprocal nature of work and psychological distress has been emphasised through disability claims in high income countries $[9,10]$, as well as the AUD 11.8 billon in productivity losses associated with poor mental health every year in Australia [55]. Given therapeutic elements like problem solving, goal setting, and cognitive restructuring are suggested to be both under-represented in, and important for, RTW interventions in the current review, this may outline an initial step forward in the RTW space. According to Comcare and Safe Work Australia guidelines, it is important that evidence-based RTW interventions include a focus on (1) early intervention, (2) therapeutic CBT-based strategies (e.g., psychoeducation, problem solving, goal setting, behavioural activation, graded exposure, pacing, and cognitive restructuring), and (3) regular measurement of progress. While results of the current review showed that a RTW focus was predominant across interventions (60\%), along with behavioural activation (67\%) and psychoeducation (57\%), a greater focus on other therapeutic strategies may be required to further improve RTW interventions 
moving forward. Despite being highlighted as important in the grey literature, strategies like problem solving, goal setting, graded exposure, pacing, cognitive restructuring, and values clarification were underrepresented in the reviewed interventions (between 0 and 36\%).

Low intensity cognitive behaviour therapy (LICBT) offers an existing evidence-based approach provided by trained behavioural health coaches that can be adapted for a RTW population, containing all the psychological aspects suggested to be important by the peak Australian RTW bodies. Originating in the UK, the efficacy, utility, and flexibility of LICBT programs targeting high prevalence mental health disorders are well documented, with recovery rates reported to between 49 and 62\% [56]. Recovery in LICBT programs is defined as the movement of those who were initially in caseness, to below caseness as measured by the psychometric measures used. LICBT programs and workbooks have been developed for varying nationalities around the world, including an Australian population [56], all of which include common elements such as psychoeducation, goal setting, and the regular measurement of psychological distress levels. Moreover, these programs and workbooks have specific focuses on behavioural activation, problem solving, graded exposure, pacing, cognitive restructuring, or worry management. Therefore, an opportunity may exist to ensure effective RTW interventions, by modifying existing LICBT support and resources to meet recommendations outlined by peak Australian RTW organisations, ensuring support is provided by trained behavioural health coaches (absent in 14 of the 18 studies in the current review), and increasing access to support via non-traditional platforms.

\section{Limitations}

Findings from this systematic review should be considered within the constraints of some methodological limitations. A meta-analysis of the included studies could not be performed due to considerable heterogeneity in RTW interventions, samples used, and the assessment of RTW outcomes across studies. These diverse elements impeded our ability to synthesise the evidence and draw reliable conclusions. Methodological weaknesses of some included studies - especially the relatively high amount of service-provision identified amongst CAU groups and limited details provided on specific intervention characteristics in some RCTs - made it difficult to determine the true effectiveness of RTW interventions and to make recommendations for specific characteristics which should be included in RTW interventions. Despite the common use of psychoeducation and behavioural activation strategies across effective RTW interventions, and their known benefits for individuals with psychological or musculoskeletal problems, it is not possible to confirm the specific role these characteristics may have played in contributing to an intervention's success. Furthermore, RTW may also be affected by other factors, such as labour market characteristics, which were not considered in this review. Most studies included in the systematic review were conducted in central and northern Europe, as such research across a wider range of contexts is needed. However, according to the grey literature included in our systematic review, several of the intervention characteristics used in the included studies are also recommended by peak bodies for RTW interventions in the Australian context, reflecting likely generalisability of results.

\section{Conclusion}

The results of this systematic review highlight the positive role psychosocial RTW interventions can play in helping people with a range of issues, from psychological to musculoskeletal problems, get back to work. The available evidence suggests that a low intensity approach to RTW interventions may be an appropriate first option before investment in more intensive and arguably more expensive approaches, as the latter appear to provide limited additional benefits. Based on the interventions scrutinized in this systematic review, and recommendations by peak Australian bodies, foundational strategies which could be used in such an intervention include those offered by a low intensity cognitive behaviour therapy framework. Despite the utility of information summarized in this systematic review, there is a need for more high-quality, rigorous RCTs to assist in providing reliable evidence to make specific recommendations about creating effective psychosocial RTW programs.

\section{Supplementary Information}

The online version contains supplementary material available at https://doi. org/10.1186/s12889-021-11898-z.

\section{Additional file 1. Peer-Reviewed Literature Search Terms.}

\section{Acknowledgements}

None to declare.

\section{Authors' contributions}

Conceptualisation: AV, TKO, JS, NT, LA; Methodology: AV, TKO, JS, NT; Formal analysis and investigation: AV, JS, TKO; Writing - original draft preparation:

TKO, AV; Writing - review and editing: AV, TKO, LA, NT, SL; Funding acquisition: AV, PR, LA, NT; Supervision: AV.

\section{Funding}

This research was funded by Remedy Healthcare Group, Melbourne, Victoria, Australia.

Availability of data and materials

Data sharing is not applicable to this article as no datasets were generated or analysed during the current study. All relevant information is included in the manuscript. 


\section{Declarations}

Ethics approval and consent to participate

Not applicable.

\section{Consent for publication}

Not applicable.

\section{Competing interest}

Authors NT and LA are employed by Remedy Healthcare Group, who funded the research. Authors AV, TKO, JS, SL, and PR have no conflicts of interest to declare.

\section{Author details}

'Discipline of Behavioural Health, College of Medicine \& Public Health, Flinders University, South Australia, Australia. ${ }^{2}$ Remedy HealthCare Group, Melbourne, Victoria, Australia. ${ }^{3}$ Discipline of Public Health, College of Medicine \& Public Health, Flinders University, South Australia, Australia.

\section{Received: 13 May 2021 Accepted: 24 September 2021}

\section{Published online: 25 November 2021}

\section{References}

1. Hoefsmit N, Houkes I, Nijhuis FJN. Intervention characteristics that facilitate return to work after sickness absence: a systematic literature review. J Occup Rehabil. 2012;22(4):462-77. https://doi.org/10.1007/s1092 6-012-9359-Z

2. de Boer AGEM, Taskila TK, Tamminga SJ, Feuerstein M, Frings-Dresen MHW, Verbeek JH. Interventions to enhance return-to-work for cancer patients. Cochrane Database of Systematic Reviews. 2015;2017(7).

3. Mikkelsen MB, Michael R. Systematic review and meta-analysis of interventions aimed at enhancing return to work for sick-listed workers with common mental disorders, stress-related disorders, somatoform disorders and personality disorders. Occup Environ Med. 2018;75(9):675-86. https:// doi.org/10.1136/oemed-2018-105073.

4. Henderson M, Glozier N, Holland EK. Long term sickness absence. BMJ (Clinical research ed). 2005;330(7495):802-3. https://doi.org/10.1136/bmj.330. 7495.802.

5. CHRC CHRC. A Guide for Managing the Return to Work.; 2007.

6. OECD OfECaD. Sickness, Disability and Work: Breaking the Barriers: A Synthesis of Findings across OECD Countries. Paris: OECD Publishing; 2010 [Available from: www.oecd-ilibrary.org/social-issuesmigration-health/ sickness-disability-and-work-breakingthe-barriers $9789264088856-e n$. [DOI: http://dx.doi.org/ https://doi.org/10.1787/9789264088856-en].

7. Arends I, Bruinvels DJ, Rebergen DS, Nieuwenhuijsen K, Madan I, NeumeyerGromen A, et al. Interventions to facilitate return to work in adults with adjustment disorders. The Cochrane database of systematic reviews. 2012; 12:Cd006389.

8. Henderson M, Harvey SB, Overland S, Mykletun A, Hotopf M. Work and common psychiatric disorders. J R Soc Med. 2011;104(5):198-207. https:// doi.org/10.1258/jrsm.2011.100231.

9. Soegaard HJ. Variation in effect of intervention studies in research on sickness absence. Open Access J Clin Trials. 2012;4:1-20. https://doi.org/1 $0.2147 /$ OAJCT.S25651.

10. OECD OfECaD. Sickness, disability and work: keeping on track in the economic downturn - background paper, 2009 Paris OECD Publishing 2009 [Available from: www.oecd.org/dataoecd/42/15/42699911.pdf. .

11. Cook L. Mental health in Australia: a quick guide. In: services DoP, editor. Commonwealth of Australia: Canberra; 2019.

12. Arthritis Australia. Burden of musculoskeletal conditions. 2016

13. Vogel N, Schandelmaier S, Zumbrunn T, Ebrahim S, de Boer WE, Busse JW, et al. Return-to-work coordination programmes for improving return to work in workers on sick leave. Cochrane Database of Systematic Reviews. 2017;2017(3).

14. Moher D, Liberati A, Tetzlaff J, Altman DG, Group P. Preferred reporting items for systematic reviews and meta-analyses: the PRISMA statement. PLoS Med. 2009;6(7):e1000097. https://doi.org/10.1371/journal.pmed.1 000097

15. Godin K, Stapleton J, Kirkpatrick SI, Hanning RM, Leatherdale ST. Applying systematic review search methods to the grey literature: a case study examining guidelines for school-based breakfast programs in Canada.
Systematic Reviews. 2015;4(1):138. https://doi.org/10.1186/s13643-015-01250.

16. Bramer WM, Rethlefsen ML, Kleijnen J, Franco OH. Optimal database combinations for literature searches in systematic reviews: a prospective exploratory study. Syst Rev. 2017;6(1):245. https://doi.org/10.1186/s13643-01 7-0644-y.

17. Loisel P, Durand M, Berthelette D, Vezina N, Baril R, Gagnon D, et al. Disability Prevention: New Paradigm for the Management of Occupational Back Pain. Disease Management and Health Outcomes. 2001;9(7).

18. IQWiG. Cognitive behavioral therapy. Cologne, Germany: Institute for Quality and Efficiency in Health Care (IQWiG); 2016.

19. Popay J, Roberts H, Sowden A, Petticrew M, Arai L, Rodgers M, et al. Guidance on the conduct of narrative synthesis in systematic reviews: a product from the ESRC methods Programme. Lancaster University. 2006.

20. Dalgaard VLP, Aschbacher KP, Andersen JHP, Glasscock DJP, Willert MVP, Carstensen OMD, et al. Return to work after work-related stress: a randomized controlled trial of a work-focused cognitive behavioral intervention. Scand J Work Environ Health. 2017;43(5):436-46. https://doi. org/10.5271/sjweh.3655.

21. Folke F, Parling T, Melin L. Acceptance and commitment therapy for depression: a preliminary randomized clinical trial for unemployed on longterm sick leave. Cogn Behav Pract. 2012;19(4):583-94. https://doi.org/10.101 6/j.cbpra.2012.01.002.

22. Netterstrøm B, Friebel L, Ladegaard Y. Effects of a multidisciplinary stress treatment programme on patient return to work rate and symptom reduction: results from a randomised, wait-list controlled trial. Psychother Psychosom. 2013;82(3):177-86. https://doi.org/10.1159/000346369.

23. Pedersen $P$, Søgaard HJ, Labriola M, Nohr EA, Jensen C. Effectiveness of psychoeducation in reducing sickness absence and improving mental health in individuals at risk of having a mental disorder: A randomised controlled trial. BMC Public Health. 2015;15(1).

24. Aasdahl L, Fimland MS. Is there really a "golden hour" for work disability interventions? A narrative review. Disabil Rehabil. 2019:1-8.

25. Aasdahl L, Pape K, Vasseljen O, Johnsen R, Gismervik S, Halsteinli V, et al. Effect of inpatient multicomponent occupational rehabilitation versus less comprehensive outpatient rehabilitation on sickness absence in persons with musculoskeletal- or mental health disorders: a randomized clinical trial. J Occup Rehabil. 2018;28(1):170-9. https://doi. org/10.1007/s10926-017-9708-z.

26. Andersen LN, Birgit J-K, Sørensen TL, Herborg LG, Roessler KK, Karen S. LONGER TERM FOLLOW-UP OF THE EFFECTS OF TAILORED PHYSICAL ACTIVITY OR CHRONIC PAIN SELF-MANAGEMENT PROGRAMME ON RETURNTO-WORK: A randomized controlled trial. J Rehabil Med. 2016;48(10):887-92. https://doi.org/10.2340/16501977-2159.

27. Bitsch BL, Nielsen CV, Stapelfeldt CM, Lynggaard V. Effect of the patient education - learning and coping strategies - in cardiac rehabilitation on return to work at one year: a randomised controlled trial show (LC-REHAB). BMC Cardiovasc Disord. 2018;18(1). https://doi.org/10.1186/s12872-0180832-2.

28. Brendbekken R, Eriksen H, Grasdal A, Harris A, Hagen E, Tangen T. Return to work in patients with chronic musculoskeletal pain: multidisciplinary intervention versus brief intervention: a randomized clinical trial. J Occup Rehabil. 2017;27(1):82-91. https://doi.org/10.1007/s10926-016-9634-5.

29. De Weerd BJ, Van Dijk MK, Van Der Linden JN, Roelen CAM, Verbraak MJPM. The effectiveness of a convergence dialogue meeting with the employer in promoting return to work as part of the cognitive-behavioural treatment of common mental disorders: a randomized controlled trial. Work. 2016;54(3): 647-55. https://doi.org/10.3233/WOR-162307.

30. Du Bois M, Donceel P. Guiding low back claimants to work: a randomized controlled trial. Spine. 2012;37(17):1425-31. https://doi.org/10.1097/BRS. Ob013e31824e4ada.

31. Finnes A, Ghaderi A, Dahl J, Nager A, Enebrink P. Randomized controlled trial of acceptance and commitment therapy and a workplace intervention for sickness absence due to mental disorders. J Occup Health Psychol 2019; 24(1):198-212. https://doi.org/10.1037/ocp0000097.

32. Glasscock DJ, Carstensen O, Vita LD. Recovery from work-related stress: a randomized controlled trial of a stress management intervention in a clinical sample. Int Arch Occup Environ Health 2018;91(6):675-87. https:// doi.org/10.1007/s00420-018-1314-7.

33. Lytsy P, Carlsson L, Anderzén I. Effectiveness of two vocational rehabilitation programmes in women with long-term sick leave due to pain syndrome or 
mental illness: 1-year follow-up of a randomized controlled trial. J Rehabil Med 2017:49(2):170-7. https://doi.org/10.2340/16501977-2188.

34. Myhre K, Marchand GH, Leivseth G, Keller A, Bautz-Holter E, Sandvik L, et al. The effect of work-focused rehabilitation among patients with neck and back pain: a randomized controlled trial. Spine. 2014;39(24):1999-2006. https://doi.org/10.1097/BRS.0000000000000610.

35. Nieuwenhuijsen K, Antonius MCS, Frings-Dresen MHW, Sluiter JK. Evaluation of a randomized controlled trial on the effect on return to work with coaching combined with light therapy and pulsed electromagnetic field therapy for workers with work-related chronic stress. BMC Public Health 2017;17(1):761. https://doi.org/10.1186/s12889-017-4720-y.

36. Park J, Esmail S, Rayani F, Norris CM, Gross DP. Motivational interviewing for workers with disabling musculoskeletal disorders: results of a cluster randomized control trial. J Occup Rehabil 2018;28(2):252-64. https://doi. org/10.1007/s10926-017-9712-3.

37. Rolving N, Nielsen CV, Christensen FB, Holm R, Bunger CE, Oestergaard LG. Does a preoperative cognitive-behavioral intervention affect disability, pain behavior, pain, and return to work the first year after lumbar spinal fusion surgery? Spine. 2015;40(9):593-600. https://doi.org/10.1186/s12889-017-472 $0-y$.

38. Salomonsson S, Santoft F, Lindsäter E, Ejeby K, Ljótsson B, Öst LG, et al. Cognitive-behavioural therapy and return-to-work intervention for patients on sick leave due to common mental disorders: a randomised controlled trial. Occup Environ Med. 2017;74(12):905-12. https://doi.org/10.1136/ oemed-2017-104342.

39. Salzwedel A, Wegscheider K, Schulz-Behrendt C, Dorr G, Reibis R, Voller H. No impact of an extensive social intervention program on return to work and quality of life after acute cardiac event: a cluster-randomized trial in patients with negative occupational prognosis. Int Arch Occup Environ Health 2019;92(8):1109-20. https://doi.org/10.1007/s00420-019-01450-3.

40. Vlasveld MC, van der Feltz-Cornelis CM, Ader HJ, Anema JR, Hoedeman R, van Mechelen W, et al. Collaborative care for sick-listed workers with major depressive disorder: a randomised controlled trial from the Netherlands depression initiative aimed at return to work and depressive symptoms. Occup Environ Med 2013;70(4):223-30. https://doi.org/10.1136/oemed-2 012-100793.

41. Volker D, Zijlstra-Vlasveld MC, Anema JR, Beekman AT, Brouwers EPM, Emons WH, et al. Effectiveness of a blended web-based intervention on return to work for sick-listed employees with common mental disorders: Results of a cluster randomized controlled trial. J Med Internet Res. 2015; $17(5)$.

42. Vonk Noordegraaf A, Anema JR, Van Mechelen W, Knol DL, Van Baal WM, Van Kesteren PJM, et al. A personalised eHealth programme reduces the duration until return to work after gynaecological surgery: results of a multicentre randomised trial. BJOG 2014;121(9):1127-35. https://doi.org/1 0.1111/1471-0528.12661.

43. Fong CJ, Murphy K, Westbrook JD, Markle M. Behavioral, Psychological, Educational and Vocational Interventions to Facilitate Employment Outcomes for Cancer Survivors: A Systematic Review. Campbell Syst Rev. 2015;11(5).

44. Palmer KT, Harris EC, Linaker C, Barker M, Lawrence W, Cooper C, et al. Effectiveness of community- and workplace-based interventions to manage musculoskeletal-related sickness absence and job loss: a systematic review. Rheumatology. 2012;51(2):230-42. https://doi.org/10.1093/rheumatology/ ker086.

45. Stergiopoulos E, Cimo A, Cheng C, Bonato S, Dewa CS. Interventions to improve work outcomes in work-related PTSD: a systematic review. BMC Public Health. 2011;11(1). https://doi.org/10.1186/1471-2458-11-838.

46. Moher D, Pham B, Jones A, Cook DJ, Jadad AR, Moher M, et al. Does quality of reports of randomised trials affect estimates of intervention efficacy reported in meta-analyses? Lancet (London, England). 1998;352(9128):609-613.

47. Mullen PD, Laville EA, Biddle AK, Lorig K. Efficacy of psychoeducational interventions on pain, depression, and disability in people with arthritis: a meta-analysis. J Rheumatol Suppl. 1987;14(Suppl 15):33-9.

48. Donker T, Griffiths KM, Cuijpers P, Christensen H. Psychoeducation for depression, anxiety and psychological distress: a meta-analysis. BMC Med. 2009; 7(1):79. https://doi.org/10.1186/1741-7015-7-79.

49. Traeger AC, Hübscher M, Henschke N, Moseley GL, Lee H, McAuley JH. Effect of primary care-based education on reassurance in patients with acute low Back pain: systematic review and Meta-analysis. JAMA Intern Med. 2015;175(5):733-43. https://doi.org/10.1001/jamainternmed.2015.0217.
50. Ekers D, Richards D, Gilbody S. A meta-analysis of randomized trials of behavioural treatment of depression. Psychol Med. 2008;38(5):611-23. https://doi.org/10.1017/S0033291707001614.

51. Ekers D, Webster L, Van Straten A, Cuijpers P, Richards D, Gilbody S. Behavioural activation for depression; an update of Meta-analysis of effectiveness and sub group analysis. PLoS One. 2014;9(6):e100100. https:// doi.org/10.1371/journal.pone.0100100.

52. van Tulder MW, Ostelo R, Vlaeyen JW, Linton SJ, Morley SJ, Assendelft WJ. Behavioral treatment for chronic low back pain: a systematic review within the framework of the Cochrane Back review group. Spine (Phila Pa 1976). 2000;25(20):2688-99. https://doi.org/10.1097/00007632-200010150-00024.

53. Morley S, Eccleston C, Williams A. Systematic review and meta-analysis of randomized controlled trials of cognitive behaviour therapy and behaviour therapy for chronic pain in adults, excluding headache. PAIN. 1999;80(1).

54. Hoffman B, Papas R, Chatkoff D, Kerns R. Meta-analysis of psychological interventions for chronic low Back pain. Health Psychol. 2007;26:9.

55. Lee Y-C, Chatterton ML, Magnus A, Mohebbi M, Le LK-D, Mihalopoulos C. Cost of high prevalence mental disorders: findings from the 2007 Australian National Survey of mental health and wellbeing. Australian \& New Zealand Journal of Psychiatry. 2017;51(12):1198-211. https://doi.org/10.1177/0004 867417710730.

56. Venning A, Oswald TK, Barnes M, Glover F, Lawn S, Azadi L, et al. It's what's under the hood that counts: comparing therapeutic outcomes when using Australian versus UK-produced clinical materials in an Australian mental health program. Australian Health Review. 2021.

\section{Publisher's Note}

Springer Nature remains neutral with regard to jurisdictional claims in published maps and institutional affiliations.
Ready to submit your research? Choose BMC and benefit from:
- fast, convenient online submission
- thorough peer review by experienced researchers in your field
- rapid publication on acceptance
- support for research data, including large and complex data types
- gold Open Access which fosters wider collaboration and increased citations
- maximum visibility for your research: over $100 \mathrm{M}$ website views per year
At BMC, research is always in progress.
Learn more biomedcentral.com/submissions 